\title{
1 Effects of pore-scale precipitation on permeability and flow
}

2

3 Catherine Noiriel ${ }^{1, *}$, Carl I. Steefel ${ }^{2}$, Li Yang ${ }^{2}$, Dominique Bernard ${ }^{3}$

$4{ }^{1}$ Géosciences Environnement Toulouse, Observatoire Midi-Pyrénées, Université Paul Sabatier, CNRS,

5 IRD, 14 avenue Edouard Belin, F-31400 Toulouse, France

$6 \quad{ }^{2}$ Earth Sciences Division, Lawrence Berkeley National Laboratory, Berkeley, CA 94720

$7 \quad{ }^{3}$ CNRS, Université de Bordeaux, ICMCB, UPR 9048, F-33600 Pessac, France

10 Catherine Noiriel * (corresponding author)

11 Géosciences Environnement Toulouse

12 UMR 5533 Université Paul Sabatier/CNRS/IRD

13 14, avenue Edouard Belin

1431400 Toulouse, France

15 catherine.noiriel@get.obs-mip.fr (tel: +33 5613330 16; fax +33 561332560 )

18 Carl Steefel CISteefel@lbl.gov

19 Li Yang lyang@lbl.gov

20 Earth Sciences Division

21 Lawrence Berkeley National Laboratory

221 Cyclotron Road, Mail Stop 90-1116, Berkeley, CA 94720.

24 Dominique Bernard bernard@icmcb-bordeaux.cnrs.fr

25 Institut de Chimie de la Matière Condensée de Bordeaux-CNRS

26 87, Avenue du Docteur Schweitzer

2733608 Pessac cedex, France 
32 Crystal growth rates and velocities are highly variable

33 Crystal shape, density and growth rate depends on mineral substrate

34 Different pore space geometry changes leads to different permeability changes

35

\section{Keywords}

37 Calcite precipitation, growth rate, growth velocity, X-ray micro-tomography, permeability, porosity 


\section{Abstract}

The effects of calcite precipitation on porous media permeability and flow were evaluated with a combined experimental and modeling approach. X-ray microtomography images of two columns packed with glass beads and calcite (spar crystals) or aragonite (Bahamas ooids) injected with a supersaturated solution ( $\log \Omega=1.42$ ) were processed in order to calculate rates of calcite precipitation with a spatial resolution of $4.46 \mu \mathrm{m}$. Identification and localization of the newly precipitated crystals on the 3D images was performed and results used to calculate the crystal growth rates and velocities. The effects of carbonate precipitation was also evaluated in terms of the integrated precipitation rate over the length of the column, crystal shape, surface area and pore roughness changes. While growth was epitaxial on calcite spar, calcite rhombohedra formed on glass beads and clusters of polyhedrons formed on aragonite ooids. Near the column inlet, calcite precipitation occurred preferentially on carbonate grains compared to glass 50 beads, with almost $100 \%$ of calcite spar surface area covered by new crystals versus $92 \%$ in the case of aragonite and $11 \%$ in the case of glass beads. Although the experimental chemistry and flow boundary conditions in the two columns were similar, their porosity-permeability evolution was different because the nucleation and subsequent crystal growth on the two substrates (i.e., calcite spar and aragonite ooids) was very different. The impact of mineral precipitation on pore-scale flow and permeability was evaluated using a pore-scale Stokes solver that accounted for the changes in pore geometry. For similar magnitude reductions in porosity, the decrease in permeability was highest within the sample that experienced the greatest increase in pore roughness. Various porous media models were generated to show the impact of different crystal growth patterns and pore roughness changes on flow and permeability-porosity relationship. Under constant flow rate boundary conditions, precipitation resulted in an increase in both the average and maximum velocities. Increases in pore roughness led to a more heterogeneous flow field, principally through the effects on the fastest and slowest velocities within the domain.

\section{Keywords}

63 Calcite precipitation, growth velocity, growth rate, porosity, permeability, X-ray microtomography.

\section{1. Introduction}

65 Mineral precipitation plays a critical role in many geological processes, including sediment diagenesis, 66 hydrothermal circulation and alteration, biomineralization, and $\mathrm{CO}_{2}$ sequestration [1-6]. Precipitation of 67 minerals like calcite can cause significant reduction in permeability and a reorganization of the flow field 
in reservoirs by altering the shape, size and connectivity of the pores, the roughness of their surfaces, and by partial or complete obstruction of flow in pore throats. Developing a full understanding of the feedbacks between geochemical reactions and flow and transport characteristics at the reservoir scale requires investigations of precipitation mechanisms at the pore-scale.

72 Three rate-determining mechanisms have been identified to describe calcite precipitation from aqueous 73 solution [7], (i) diffusive transport and/or adsorption of lattice ion, (ii) surface spiral growth, and (iii) 74 surface nucleation involving polynuclear growth. These mechanisms involve different dependences of the 75 precipitation rate, $r_{p p t}\left(\mathrm{~mol} \cdot \mathrm{m}^{-2} \cdot \mathrm{s}^{-1}\right)$, on the supersaturation $(1-\Omega)$ :

$76 \quad r_{p p t}=k\left[\exp \left(\frac{m \Delta G}{R^{*} T}\right)-1\right]^{n}=k\left(\Omega^{m}-1\right)^{n}$

77 with $k$ the rate constant $\left(\mathrm{mol} \cdot \mathrm{m}^{-2} \cdot \mathrm{s}^{-1}\right), \Delta G$ the Gibbs free energy change of the overall reaction $\left(\mathrm{J} \cdot \mathrm{mol}^{-1}\right)$, $78 \Omega$ the saturation index, $R^{*}$ the gas constant $\left(\mathrm{J} \cdot \mathrm{K}^{-1} \cdot \mathrm{mol}^{-1}\right), T$ the absolute temperature $(\mathrm{K})$, and $n$ and $m$ the 79 semi-empirical constants that depend on the kinetic behavior involved in the chemical reaction. Here $r_{p p t}$ 80 is the rate normalized against the reactive surface area, $S_{r}\left(\mathrm{~m}^{2}\right)$. A value of $n=1$ (linear rate law) has been 81 attributed to crystallization limited by adsorption of lattice ions [7], and in some cases to a multi-source 82 spiral growth mechanism [8]. A second order equation $(n=2)$ may be used to describe growth at single 83 screw dislocation by the spiral mechanism [8], while higher order dependences $(n>2)$ can be applied to 84 growth both at screw and edge dislocation [9] or growth by 2D nucleation [8].

85 Porosity-permeability evolution in rocks results from the interplay between reaction kinetics and mass 86 transport. Two parameters, i.e., the Péclet $(\mathrm{Pe})$ and Damköhler (Da) numbers, defined locally as: $87 \mathrm{Pe}=u L^{*} / D_{m}$ and $\mathrm{Da}=k_{r} L^{* 2} / D_{m}$, where $u$ is the fluid velocity $\left(\mathrm{m} \cdot \mathrm{s}^{-1}\right), D_{m}$ is molecular diffusion $\left(\mathrm{m}^{2} \cdot \mathrm{s}^{-}\right.$ $\left.8{ }^{1}\right), k_{r}$ is a first order kinetic constant $\left(\mathrm{s}^{-1}\right)$, and $L^{*}$ is a characteristic length (m), e.g., the pore size [10, 11], 89 are commonly used to describe the physical evolution of the pore space to capture the possible feedback 90 between the flow regime and the geochemical alteration, e.g., [12-15]. Although precipitation of calcite in 91 natural systems is often assumed to be kinetically-controlled, i.e., independent of mass transport rates [16], 92 precipitation rates can vary along flow paths due to changes in the fluid saturation index, temperature and 93 pressure, and the presence of bacterial communities, inhibitors or (in)organic impurities [17-31]. In 94 addition, several studies have reported that both crystal location, morphology and growth rate are closely 95 related to the mineral surface properties [17, 32-36], which make mineralogical heterogeneities of the pore 96 walls an important factor for understanding calcite nucleation and growth in porous media. 
The distribution of new precipitates leads to a decrease of porosity with resulting changes in the pore-size distribution, and in some cases, in pore roughness. These effects in turn can modify flow and permeability. Description of permeability evolution in the presence of pore-scale heterogeneities is still challenging, as micro-heterogeneities are often ignored in flow and reactive transport codes at the macroscopic (or Darcy) scale.

Most permeability reduction models consider at least an exponential or power-law dependence of permeability to porosity, and sometimes integrate the effects of tortuosity, shape factor, specific surface area or pore shape [37-39]. Using a simple model of cylindrical pores, Ghezzehei [40] established differences in permeability of up to three orders of magnitude between uniform and non-uniform precipitation models. The uniform model corresponds to a coating of the cylindrical pore with precipitate of uniform thickness, while in the non-uniform model the pore contains several rectangular precipitate crystals of various sizes separated by equal distance. The author proposed a modified formulation of the Kozeny-Carman model [37] to correct for pore-scale distribution of the precipitates. Although this model has been extensively modified to improve the estimation of the permeability when porosity changes, it seems that modifications at micro-scale are too diverse to be captured by only a small number of macroscale parameters such as porosity and/or tortuosity of cylindrical pores.

Advances in non-invasive and non-destructive techniques like X-ray microtomography (XMT) have allowed for characterization of flow or geometry changes over time at the pore-scale during dynamic processes or experiments, see e.g., $[14,41]$ for a review. In particular, characterization of pore geometry and pore-space distribution is possible [42-44]. The dynamics of the fluid-rock interface can also be followed through time $[45,46]$. Even if it is difficult to define pore roughness to the extent that it depends on the resolution and scale of observation, the changes in pore or surface roughness can be examined [47]. The 3D geometry derived in this way can be used for discrete calculations of porous media properties such as permeability and transport, e.g., see [48] for a review.

The present study is focused on the effects of calcite precipitation on changes in pore geometry, permeability and flow at the pore-scale. These effects are investigated both experimentally and numerically through an idealized representation of porous rock columns representing very simple analogs of a calcareous sandstone. Glass beads and calcite spar crystals or aragonite ooids were selected to test the effects of the substrate composition on precipitation under similar chemistry and flow conditions. The characterization of the pore structure, which is crucial for determination of flow in porous media, was carried out before and after precipitation experiments using X-ray microtomography (XMT) at a resolution of $4.46 \mu \mathrm{m}$. The first part of the paper is devoted to the identification, localization and characterization of the newly precipitated crystals and to the determination of crystal growth velocity and 
growth rate from XMT images. The discrete 3D geometry is then used as an input for permeability calculations, and several models of precipitation were generated and examined to test the effects of precipitation-induced micro-scale changes on permeability and flow properties.

\section{Experimental and modeling procedure}

Experiments were designed to study the effects of precipitation and substrate composition in columns packed with glass beads and calcite crystals or aragonite ooids. X-ray microtomography (XMT) allowed for the investigation of the crystallization processes in porous media by monitoring changes in porosity, pore geometry, and surface roughness. Because of the high initial porosity and permeability of the columns, experimental determination of permeability based on the pressure difference between the inlet and outlet was not possible. Instead, permeability was computed directly from the 3D discrete geometry of the samples after image segmentation using a Stokes solver.

\subsection{Precipitation experiments}

Two samples (REAC-1 and REAC-3) consisting of the contents of cylindrical plug-flow column reactors of $6.5 \mathrm{~mm}$ diameter and approximately $12 \mathrm{~mm}$ length were prepared by packing a mixture of glass beads and crushed calcite spar or aragonite ooids (Table 1, see also [36] for more details about sample REAC-1). The glass beads used here were acid-washed soda-lime glass in the range 425-600 $\mu \mathrm{m}$ (Sigma G8772). Calcite that began as centimeter-size Iceland spar crystals was crushed in an agate mortar and then sieved in the range 355-500 $\mu \mathrm{m}$. Aragonite ooids, which come from oolithic sand sampled on the seabed in Bahamas, were also sieved in the range 355-500 $\mu \mathrm{m}$. All the materials were washed with deionized water, cleaned ultrasonically, and dried at $50^{\circ} \mathrm{C}$ prior to column assembly.

Each reactor was injected with a 50/50 mixture of $0.002 \mathrm{M} \mathrm{CaCl}_{2}$ and $0.004 \mathrm{M} \mathrm{NaHCO}_{3}$ at a flow rate of $0.5 \mathrm{~cm}^{3} \cdot \mathrm{h}^{-1}\left(\mathrm{Q}=1.3810^{-10} \mathrm{~m}^{3} \cdot \mathrm{s}^{-1}\right)$ using a multi-channel syringe pump (Figure 1), inducing a calcite saturation index $(\log \Omega)$ of 1.42 (see [36] for calculation details). The reactors were saturated with deionized water under vacuum prior to experiments and injected with an acidic solution (deionized water $+\mathrm{HCl}, \mathrm{pH} 4.0)$ for $5 \mathrm{~h}$ at a flow rate of $20 \mathrm{ml} \cdot \mathrm{h}^{-1}\left(\mathrm{Q}=5.5610^{-9} \mathrm{~m}^{3} \cdot \mathrm{s}^{-1}\right)$ to further clean the mineral surfaces and eliminate fine particles.

The experiments were conducted at room temperature $\left(22^{\circ} \mathrm{C}\right)$ over either 30 days (REAC-1) or 15 days (REAC-3). The second experiment (REAC-3) was stopped at 15 days after clogging of the column inlet. 158 The $\mathrm{pH}$ of both the inlet and outlet solutions was measured using an Orion $\mathrm{pH}$ electrode. In addition, 159 major and minor elements were measured in solution by inductively coupled plasma mass spectroscopy 
(ICP-MS), after acidification with nitric acid $(\mathrm{pH}<2)$. After the experiments were finished, materials of the inlet and exit portions of each column were collected for scanning electron microscopy (SEM) observations. Raman spectroscopy was used to determine the identity of the calcium carbonate precipitates. Only calcite was found as a precipitate on both carbonate or glass bead surfaces.

164 The overall calcite precipitation rate $\left(\mathrm{mol} \cdot \mathrm{s}^{-1}\right)$ through the columns is calculated from the chemical 165 analysis of the column effluent (outlet) as:

$166 \quad r_{p p t}=\frac{1}{v_{c a l}} \frac{\Delta V_{c a l}}{\Delta t}=Q \times \overline{\Delta \mathrm{Ca}}$

167 with $V_{\text {cal }}$ the volume of precipitated calcite, $Q$ the volumetric flow rate $\left(\mathrm{m}^{3} \cdot \mathrm{s}^{-1}\right), v_{\text {cal }}$ the molar volume of 168 calcite $\left(\mathrm{m}^{3} \cdot \mathrm{mol}^{-1}\right)$, and $\overline{\Delta \mathrm{Ca}}$ the average variation in calcium concentration $\left(\mathrm{mol} \cdot \mathrm{m}^{-3}\right)$ between the inlet and 169 the outlet of the column during the experiment.

Table 1. Composition of the plug-flow columns.

\begin{tabular}{|c|c|c|}
\hline Sample name & REAC-1 & REAC-3 \\
& $\begin{array}{c}\text { Precipitation on calcite spar } \\
\text { and glass beads }\end{array}$ & $\begin{array}{c}\text { Precipitation on aragonite } \\
\text { ooids and glass beads }\end{array}$ \\
\hline Mass $(\mathrm{g})$ & 0.6300 & 0.6699 \\
\hline Carbonate $(\% \mathrm{w})$ & $25^{*}$ & $26^{* *}$ \\
\hline Glass beads $(\% \mathrm{w})$ & 75 & 74 \\
\hline
\end{tabular}

$172 \quad$ *alcite spar; ${ }^{* *}$ aragonite

175 Figure 1. Schematic of the plug-flow column experimental setup

\section{$176 \quad$ 2.2. Image acquisition and processing}

177 The geometry of the two packed columns was characterized with X-ray microtomography (XMT) at 178 Beamline 8.3.2 at the Advanced Light Source of Lawrence Berkeley National Laboratory. The optical 179 system used in the experiment, i.e., a Mitutoyo $\times 2$ lens combined with a Cooke PCO4000 CCD camera, 180 provided a spatial resolution of $4.46 \mu \mathrm{m}$ (voxel size). 
Two XMT datasets were collected for each column, both before (initial time, $t_{0}$ ) and after (final time, $t_{1}$ ) each experiment. The X-ray source was diffracted through a multilayer, yielding a focused monochromatic and parallel beam with energy of $28 \mathrm{keV}$. Exposure time for each radiograph was $700 \mathrm{~ms}$. 3D image reconstruction was performed from 1441 radiographs taken over $180^{\circ}$ using the software package Octopus [49] and image processing carried out using Avizo ${ }^{\circledR}$ software on data sets of $1600 \times$ $1600 \times 3000$ voxels. Image processing procedure, including noise reduction, segmentation and registration is described in [36].

Several volumes of interest (VOI) were extracted from the original datasets for quantification. Columnscale volumes of $1000 \times 1000 \times 1000$ voxels and pore-scale sub-volumes of either $300 \times 300 \times 300$ voxels or $350 \times 350 \times 350$ voxels were extracted near the column inlets, where precipitation was highly visible. The VOI were named according to the volume size, column name, and stage of experiment (Table 2).

Table 2. Description of the volumes of interest (VOI) extracted from original datasets for quantification and flow computation.

\begin{tabular}{|c|c|c|c|}
\hline Volume of interest (VOI) & Sample & Stage & Size (voxels) \\
\hline Vol-REAC-1-initial & \multirow{4}{*}{$\begin{array}{c}\text { REAC-1 } \\
\text { Precipitation on calcite spar } \\
\text { and glass beads }\end{array}$} & initial & \multirow{2}{*}{$1000 \times 1000 \times 1000$} \\
\hline Vol-REAC-1-final & & final & \\
\hline SubVol-REAC-1-initial & & initial & \multirow{2}{*}{$300 \times 300 \times 300$} \\
\hline SubVol-REAC-1-final & & final & \\
\hline Vol-REAC-3-initial & \multirow{4}{*}{$\begin{array}{l}\text { REAC-3 } \\
\text { pitation on aragonite } \\
\text { ds and glass beads }\end{array}$} & initial & \multirow{2}{*}{$1000 \times 1000 \times 1000$} \\
\hline Vol-REAC-3-final & & final & \\
\hline SubVol-REAC-3-initial & & initial & \multirow{2}{*}{$350 \times 350 \times 350$} \\
\hline SubVol-REAC-3-final & & final & \\
\hline
\end{tabular}

After segmentation of the XMT images, the total porosity of the sample $\phi$ is the ratio of the pore space 197 to the total volume. The local porosity $\phi(z)$ can also be calculated for each slice along the flow axis. It is 198 also possible to calculate the rate of calcite precipitation from the difference in the number of solid voxels 199 (or pixels) observed at the end $\left(t_{1}\right)$ and at the beginning $\left(t_{0}\right)$ of the experiment. The overall precipitation 200 rate $\left(\mathrm{mol} \cdot \mathrm{s}^{-1}\right)$ obtained from XMT is expressed as: 


$$
r_{p p t}^{\prime}=\frac{1}{v_{c a l}} \frac{\Delta V_{c a l}^{\prime}}{\Delta t}=\frac{\sum_{V O I} N_{c a l}\left(t_{1}\right)-N_{c a l}\left(t_{0}\right) \times V_{p i x}}{t_{1}-t_{0}}
$$

with $V_{c a l}^{\prime}$ the volume of precipitated calcite calculated from XMT, $N_{c a l}$ the number of calcite voxels in the image, and $V_{p i x}$ the volume of a voxel $\left(V_{p i x}=4.46 \times 4.46 \times 4.46 \mu \mathrm{m}^{3}\right)$.

\subsubsection{Mineral separation and quantification}

Every grain (i.e., either calcite spar or aragonite ooid and glass bead) was also individually mapped in the individual volumes of interest. From the binary images, the 3D Euclidean distance map based on a 34-5 chamfer distance transform [50,51] was computed in order to identify the centroids of the different grains. Following this, a fast 3D watershed algorithm [52] was applied to invert the distance map in order to find the separation lines around the different centroids that correspond to the contact areas between grains. Once separated, every grain and contact area was labeled. For REAC-1, it was possible to discriminate between spar crystal and glass beads based on the difference in sphericity of the grains using a threshold value of 0.83 . The sphericity, $\psi$, is defined as: $\psi=\pi^{1 / 3}\left(6 V_{\text {grain }}\right)^{2 / 3} / S_{\text {grain }}$, with $V_{\text {grain }}$ the volume and $S_{\text {grain }}$ the surface area of the grains, respectively. The procedure is illustrated in Figure 2. For REAC-3, the morphological descriptors were less efficient for this sample since glass beads and aragonite ooids have very similar morphologies. As a result, some of the grains had to be labeled manually from visual inspection, particularly the truncated ones near the VOI edges.

Once labeled, the surface area $S_{m a t}\left(\mathrm{~m}^{2}\right)$ of the different materials (i.e., calcite spar, glass beads or aragonite ooids) could be calculated as the number of pore-material pixels $N_{\text {mat-fluid }}$ multiplied by their surface-area $\left(S_{p i x}=4.46 \times 4.46 \mu \mathrm{m}^{2}\right)$. The geometric surface-area normalized to the volume of material, $S_{m a t}^{\prime}\left(\mathrm{m}^{2} \cdot \mathrm{m}^{-3}\right)$, is defined by:

$$
S_{\text {mat }}^{\prime}=\sum_{V_{T}} N_{\text {mat-fluid }} \times S_{\text {pix }} / V_{\text {mat }}
$$

with $V_{m a t}$ the material volume. The ratio of final surface area of the different materials to their initial surface area , $S / S_{0}$, with $S_{0}\left(\mathrm{~m}^{2}\right)$ the surface area before experiment., provides a good indicator of the changes in surface roughness during the experiment, i.e.,:

$$
S / S_{0}=\sum_{m a t} S_{m a t} / S_{0 m a t}
$$


Figure 2. Glass beads and calcite spar crystals separation and labeling. (a) Grayscale image (size: $4.46 \times 4.46 \mathrm{~mm}$ ), Vol-REAC-1-initial (calcite spar: high grayscale, glass bead: intermediate grayscale, porosity: low grayscale). (b) Segmentation and separation of every grain (in blue), i.e., calcite spar and glass beads, in the image. (c) Shape-based identification and labeling of individual glass beads (color scale). Note that mislabeling of truncated spheres (those with a sphericity $<0.83$ ) occurred near the edges of the image.

\subsubsection{Precipitation localization and growth velocity}

Image difference between final and initial pore-scale sub-volume was also computed for REAC-3 in order to identify which of the new crystals had grown on aragonite ooids versus the glass beads. It was not possible to apply the procedure to REAC-1 due to slight displacement of some glass beads. Where a slight displacement occurred, volume subtraction failed to map the target volume to the reference one. Newly precipitated crystals were labeled individually after cleaning with an erosion-dilatation filter. The growth velocity $\left(\mu \mathrm{m} \cdot \mathrm{d}^{-1}\right)$ of individual crystals was calculated based on the change in crystal length normal to the substrate surface, as:

$$
v_{\text {growth }}=\frac{d \mathbf{I}_{\mathbf{f}} \cdot \mathbf{n}}{d t}
$$

244 with $\mathbf{I}_{\mathbf{f s}}$ the vector position of the fluid-solid interface and $\mathbf{n}$ the normal to the substrate surface. Crystal 245 length normal to the substrate surface was determined by combining a 3D Euclidean distance map of the 246 newly formed crystals compared to the initial material. The map is based on a 3-4-5 chamfer distance 247 transform [50, 51], and labels each pixel of the newly formed crystals with the distance to the nearest 248 boundary pixel [53], starting from the initial position of the fluid-solid interface. Local maximum of the 249 distance map for every newly formed crystal gives their maximal length. In addition, the average crystal 250 growth rate $\left(\mathrm{mol} \cdot \mathrm{s}^{-1}\right)$ can be calculated from the volume of precipitated crystals:

$$
r_{\text {growth }}=\frac{1}{v_{\text {cal }}} \int_{\text {Vcryst }} \frac{d V_{\text {cryst }}}{d t}
$$

with $V_{\text {cryst }}$ the crystal volume $\left(\mathrm{m}^{3}\right)$. The procedure is illustrated in Figure 3.

Figure 3. Crystal growth velocity and growth rate distribution within pore-scale volume SubVREAC-3. (a) Identification between newly precipitated crystals on glass beads and on aragonite 256 ooids from image difference. (b) Distance map of the new crystals normal to their substrate; the 
maxima are dotted in blue. The color scale denotes the distance of every pixel of the newly formed crystal from the fluid-rock interface they are attached to. (c) Growth velocity distribution $\left(\mu \mathrm{m}^{\cdot \mathrm{d}^{-1}}\right)$ based on maximum crystal length. (d) Crystal growth rate $\left(\mathrm{mol}^{-1} \mathrm{~s}^{-1}\right)$ based on crystal volume. Note

\subsection{Flow model}

The complete permeability tensors $\overline{\bar{k}}$ were obtained by solving the closure problem associated with the volume averaging of the Stokes' equations within the fluid phase [54], assuming that the inertial forces were negligible:

$$
\left\{\begin{array}{l}
\nabla \mathbf{u}=0 \\
\mu \nabla^{2} \mathbf{u}-\nabla P=0
\end{array}\right.
$$

with $\mathbf{u}=\left[u_{x} u_{y} u_{z}\right]$ the fluid velocity vector, $\mu$ the viscosity and $\mathrm{P}$ the pressure. A solver implemented in Avizo $^{\circledR}$ under the XLabHydro package was used. Details about the solver can be found in [55]. Spatial discretization is carried out following the classical finite volume method [56]. The discretized system is solved numerically on a staggered grid with a cubic grid spacing of $4.46 \mu \mathrm{m}$ defined directly from the XMT images. Time integration is carried out using a fully explicit scheme for which a stability criterion of $27210^{-4}$ was chosen so as to obtain a symmetrical tensor with a precision of 3 digits. Determination of the 273 permeability tensor components in the $x$ - and $y$-directions (i.e., perpendicular to the flow direction) 274 directly on the columns was not possible due to their elongated cylindrical shape, as the use of periodic boundary conditions requires that the inflow and outflow boundaries match. The calculations were performed instead on cubic volumes extracted from the columns, i.e., the column-scale volumes of interest of REAC-1, and also on the different pore-scale volumes of REAC-1 and REAC-3 (Table 2).

The velocity field was also resolved in the fluid flow direction in the pore-scale volumes using a flow solver of the Stokes' equations. The advantage of this solver over the calculation of the permeability tensor is that it is possible to calculate the flow properties in the conditions of experiments, e.g., the velocity magnitude (at the voxel center): $u=\|\mathbf{u}\|=\sqrt{\mathbf{u} \cdot \mathbf{u}}$, and the average velocity magnitude: $\bar{u}$. Boundary conditions are constant volumetric flux $(q=Q \times s / S$, with $\mathrm{Q}$ the experiment flow rate, $\mathrm{S}$ the column sectional area, s the considered volume sectional area) at the inlet, constant pressure at the outlet $\left(10^{5} \mathrm{~Pa}\right.$, i.e., atmospheric pressure) and no-flow for the other faces. Inflow and outflow zones are added to accommodate the complex porous shape at the inlet and outlet of the volumes and to increase numerical 286 stability. Periodicity is forced for fluid velocity at the inlet and outlet. The pressure is solved at the center 
of the grid and the velocity is solved at the boundary of the grid using an artificial compressibility scheme [57]. After pressure and flow fields are resolved, pressure drop $(\Delta P)$ between inlet and outlet is used to calculate permeability $k_{D}\left(\mathrm{~m}^{2}\right)$ from Darcy's law [58]. Darcy's seepage velocity is calculated as:

\section{Results}

\subsection{Calcite nucleation and growth}

Precipitation occurred preferentially near the inlet of the columns where the supersaturation with respect to calcite was the highest. In this region, the newly precipitated crystals are both larger and more numerous. The shape, number, and size of the crystals, however, are closely linked to the substrate for precipitation (Figure 4) and the saturation index. Nucleation is favored on calcite compared to aragonite and glass beads. Crystal growth on calcite spar is epitaxial, i.e., crystallographically oriented on the single spar surfaces; as a result, the newly formed crystals cover the spar surface as a homogenous layer (Figure 5a). In contrast, single individual crystals are observed on both aragonite and glass beads, but with differing shapes, orientations, densities and sizes (Figure 4 and Figure 5). The surface of glass beads display sparsely distributed rhombohedral crystals (Figure 5b), while the surface of aragonite ooids is covered by many polyhedral crystals that are aggregated (Figure $5 \mathrm{c}, \mathrm{d}$ ).

For sample SubVol-REAC-1, the volume of new crystals precipitated on calcite spar was 4.7 times higher than on glass beads. The new crystals cover almost $100 \%$ of the surface area of calcite spar, except near the contact areas with glass beads (Figure 6). For sample SubVol-REAC-3, the volume of new crystals precipitated on aragonite ooids was 3.7 times higher than on glass beads. In the case of SubVolREAC-3, the new crystals cover only $11 \%$ of the surface area of glass beads, while $92 \%$ of the surface area of aragonite ooids was covered. A higher density of nucleation sites on calcite spar or aragonite compared with glass beads likely explains the greater number of new crystals precipitated on carbonate phases.

Figure 4. XMT observation of pore-scale volumes extracted near columns inlets before (initial) and after (final) experiment. (a) SubVol-REAC-1 $\left(1.34 \times 1.34 \times 1.34 \mathrm{~mm}^{3}\right)$. (b) SubVol-REAC-3 $\left(1.56 \times 1.56 \times 1.56 \mathrm{~mm}^{3}\right)$. Precipitation is visible on the final volumes. 
Figure 5. Scanning electron microscope (SEM) observations of the surface of (a) calcite spar crystal, (b) glass bead, and (c) and (d) aragonite ooid after experiment. Note that the areas where no precipitation occurred in (c) correspond to contact areas with other grains.

Figure 6. 3D rendering of precipitation on a calcite spar crystal, sample REAC-1. The yellow volume was obtained by image difference and corresponds to the precipitation on the outer surface of spar crystals (transparent) during the experiment. Precipitation is not detectable near the contact with glass beads (arrows).

\subsection{Precipitation and growth rate}

The chemical composition of the inlet and outlet solutions show a decrease of calcium concentration over the length of the column $(\Delta \mathrm{Ca}>0)$ as a result of calcite precipitation. At the column scale, the overall precipitation rate is more than two times higher for the experiment with calcite spar and glass beads $\left(r_{p p t} R_{R E A C-1}=5.510^{-11} \mathrm{~mol} \cdot \mathrm{s}^{-1}\right.$ for $\left.\overline{\Delta \mathrm{Ca}}=4.010^{-4} \mathrm{M}\right)$ compared to aragonite ooids and glass beads $\left(r_{p p t} R_{R E A C-3}=2.910^{-11} \mathrm{~mol} \cdot \mathrm{s}^{-1}\right.$ for $\left.\overline{\Delta \mathrm{Ca}}=2.010^{-4} \mathrm{M}\right)$. By comparison, rates measured from XMT are 5.2 $10^{-11} \mathrm{~mol} \cdot \mathrm{s}^{-1}$ for REAC-1, and $1.810^{-11} \mathrm{~mol} \cdot \mathrm{s}^{-1}$ for REAC-3. As glass bead and carbonate proportions are almost equal for the two columns, different rates indicate that the rate of precipitation on the calcite spar crystals is higher than on the aragonite ooids. Differences in the rate can be explained by the differences in reactivity of calcite surfaces compared to those of aragonite. In fact, newly precipitated calcite was observed with SEM on calcite spar over the entire length of the column, as there is a nucleation threshold for aragonite (which is nevertheless lower than for glass beads on which new crystals were observed to nucleate only within the first $1.8 \mathrm{~mm}$ of the columns).

At the pore-scale, the crystals grown on glass beads were often larger than those grown on the nearby aragonite ooids even though the saturation index and the flow conditions were nearly identical. In addition, the crystals formed on the two substrates show very different growth velocities and average growth rates (Figure 7). Statistical details calculated on pore-scale Subvol-REAC-3 are given in Table 3. The growth velocity of new crystals on glass beads is higher on average but also more disperse. In contrast, the average growth rate of individual crystals is lower on aragonite ooids. This is largely because many of the new crystals labeled on aragonite are actually aggregated and form clusters, the volume of which is higher than for individual crystals. 


\begin{tabular}{|l|c|c|}
\hline SubVol-REAC-3 & $\bar{v}_{\text {growth }} \pm \sigma\left(\mu \mathrm{m} \cdot \mathrm{d}^{-1}\right)$ & $\bar{r}_{\text {growth }} \pm \sigma\left(\times 10^{-15} \mathrm{~mol} \cdot \mathrm{s}^{-1}\right)$ \\
\hline New crystals on aragonite & $3.9 \pm 2.8$ & $1.7 \pm 4.8$ \\
\hline New crystals on glass beads & $4.6 \pm 5.0$ & $1.1 \pm 2.2$ \\
\hline
\end{tabular}

Figure 7. Growth velocity distribution of new calcite crystals on glass beads and aragonite ooids

\subsection{Changes in surface area and roughness}

Changes in surface roughness were studied through changes of the surface area from pore-scale volumes. Because of the strong dependence of precipitation on the mineral substrate, the roughness and surface area changes are very different between the two columns. For SubVol-REAC-1 (i.e., experiment using calcite spar and glass beads), the roughness of the calcite spar crystals changes at the micro-scale due to $2 \mathrm{D}$ heterogeneous and spiral growth, but these changes occur at a very small scale (Figure 5a, see also [36] for discussion) and are not visible at the resolution of XMT imaging, thus the crystals appear to remain flat. The total surface area increases by only $5 \%$ due to calcite precipitation. We calculated an increase of the surface area of calcite spar as $7 \%$, while the increase on glass beads was $3 \%$. In contrast, 369 the growth of individual crystals at the surface of aragonite and glass beads induces complex precipitation with aragonite ooids and glass beads), the entire surface area increases by $20 \%$ as a result of calcite precipitation. An increase of the surface area of aragonite of $41 \%$ was calculated, while the increase was only $7 \%$ for the glass beads. 
Table 4. Porosity and permeability changes within the volumes of interest (VOI)

\begin{tabular}{|c|c|c|c|c|c|c|c|c|}
\hline VOI & \multicolumn{2}{|c|}{ Vol-REAC-1 } & \multicolumn{2}{|c|}{ Vol-REAC-3 } & \multicolumn{2}{|c|}{ Subvol-REAC-1 } & \multicolumn{2}{|c|}{ Subvol-REAC-3 } \\
\hline \multirow[t]{3}{*}{ Size (voxel) } & \multirow{2}{*}{\multicolumn{2}{|c|}{$\begin{array}{c}1000 \times 1000 \times \\
1000\end{array}$}} & \multirow{2}{*}{\multicolumn{2}{|c|}{$\begin{array}{c}1000 \times 1000 \times \\
1000\end{array}$}} & \multirow{2}{*}{\multicolumn{2}{|c|}{$300 \times 300 \times 300$}} & \multirow{2}{*}{\multicolumn{2}{|c|}{$350 \times 350 \times 350$}} \\
\hline & & & & & & & & \\
\hline & initial & final & initial & final & initial & final & initial & final \\
\hline
\end{tabular}

\subsection{Porosity, permeability and flow changes}

Estimated porosity and permeability changes are presented for the different volumes of interest in Table 4. Both porosity and permeability changes differ between the column-scale and the pore-scale volumes, as precipitation was not uniform over the column length. As mentioned above, precipitation primarily occurred near the inlet of the columns where the supersaturation was the highest, with the result that porosity reduction is higher near the column inlet (Figure 8). For the pore-scale volume SubVolREAC-1, permeability in the flow direction, $k_{z z}$, decreases from $9610^{-12}$ to $6010^{-12} \mathrm{~m}^{2}$ for a porosity reduction of $3.9 \%$ (from 36.2 to $32.3 \%$ ). The variations are quite comparable for the sub-volume SubVolREAC-3, with permeability in the flow direction decreasing from $11510^{-12}$ to $6210^{-12} \mathrm{~m}^{2}$ for a porosity reduction of $3.5 \%$ (from 36.3 to $32.8 \%$ ). The average fluid velocity magnitude in the flow direction increases from 19.5 to $22.5 \mu \mathrm{m} \cdot \mathrm{s}^{-1}$ for SubVolREAC-1, and from 14.3 to $16.3 \mu \mathrm{m} \cdot \mathrm{s}^{-1}$ for SubVolREAC-3.

Changes in permeability are closely linked to the closing of pore throats associated with porosity reduction, but also to the increase in roughness at the surface of the aragonite and glass beads. Distribution of the velocity magnitude $u$ along the main flow direction shows similar trends between SubVolREAC-1 and SubVolREAC-3. The distribution of the fluid velocity magnitude normalized to the Darcy's seepage velocity, $\bar{u} / u_{P}$, is presented in Figure 9 as $\log -\log$ and semi-log plots. The magnitude of the principal velocity peak is centered on approximately $\bar{u} / u_{P}=1.36$. Precipitation results in both REAC-1 and REAC3 in: (1) an increase of the frequency of locations of the slowest velocities (underlined with an arrow in Figure 9a), (2), an increase of the highest velocities (underlined with an arrow in Figure 9b), and (3) a decrease of the magnitude of the principal velocity peak resulting from an increase of the standard deviation of the fluid velocity distribution (Table 5). However, for REAC-3 (i.e., aragonite and glass beads) the volume of the pore space within which the velocity decreases is far greater. Although fluid velocity does not seem to be disturbed in the vicinity of the smooth grains (i.e., calcite spar and glass beads), the velocity decrease in the vicinity of rough grains (i.e., aragonite) is more pronounced (Figure $9 \mathrm{c}, \mathrm{d})$. 


\begin{tabular}{|l|c|c|c|c|c|c|c|c|}
\hline$\phi(\%)$ & 35.9 & 34.6 & 35.9 & 34.8 & 36.3 & 32.3 & 36.3 & 32.8 \\
\hline$k_{z z}\left(\times 10^{-12} \mathrm{~m}^{2}\right)$ & 198 & 170 & - & - & 112 & 69 & 137 & 77 \\
\hline$k_{D}\left(\times 10^{-12} \mathrm{~m}^{2}\right)$ & - & - & - & - & 115 & 79 & 111 & 67 \\
\hline $\bar{u} \pm \sigma\left(\mu \mathrm{m} \cdot \mathrm{s}^{-1}\right)$ & - & - & - & - & $19.5 \pm$ & $22.3 \pm$ & $14.3 \pm$ & $16.3 \pm$ \\
& & & & & 14.6 & 16.2 & 10.3 & 11.9 \\
\hline$u_{P}\left(\mu \mathrm{m} \cdot \mathrm{s}^{-1}\right)$ & - & - & - & - & 11.5 & 12.8 & 11.6 & 13.0 \\
\hline
\end{tabular}

Figure 8. Porosity changes along the flow direction during the experiments for the column-scale volumes of interest Vol-REAC-1 (calcite and glass) and Vol-REAC-3 (aragonite and glass).

Figure 9. Fluid velocity distribution in pore-scale volumes SubVol-REAC-1 calcite and glass) and SubVol-REAC-3 (aragonite and glass) before and after experiment, respectively. (a) and (b) Histograms of normalized velocity magnitude in log-log and semi-log plots, respectively. (c) and (d) example of 2D cross-section of the fluid velocity along the principal flow direction.

\section{Pore evolution model}

413 Imaging of the 3D geometry of the samples has shown that the density, shape and size of the newly 414 precipitated crystals depended strongly on the pre-existing substrate surface properties. Although the 415 experimental chemistry and flow boundary conditions in samples REAC-1 and REAC-3 were similar, 416 their porosity-permeability evolution is very different because (1) the initial geometry was different, and 417 (2) the geometry modifications resulting from precipitation on calcite spar compared with aragonite ooids 418 were quite different. To overcome the differences in the initial geometry of the columns (or samples), we 419 tested for the influence of precipitation patterns on permeability evolution of pore-scale volumes that are 420 directly comparable. To do that, a random growth model was used to generate different cases (or 421 scenarios) of precipitation, from highly uniform to highly non-uniform, within the same starting porous 
medium. Then, permeability and flow changes were computed in the new generated volumes at two stages

\subsection{Description of the model and scenarios of precipitation}

Volume SubVol-REAC-1-initial was used as initial porous medium for all the precipitation cases studied. Four phases were identified in this starting volume: the fluid phase, the contact surfaces between grains, and two different solid phases, labeled as solid 1 and solid 2. Solid 1 corresponds to the original glass beads and solid 2 corresponds to the calcite spar crystals.

The random growth model is used to nucleate and grow new crystals in the fluid phase from one or several fluid-solid interfaces, i.e., at the surface of solid 1 and/or solid 2. Homogeneous nucleation (i.e., directly from solution) was not allowed (or considered).

The new crystals are added through a number of discrete steps. First, a nucleation stage consists of attaching the center of gravity of nuclei to the solid surface. The nuclei, which are defined as cubes of 27 voxels (i.e., $13.38 \times 13.38 \times 13.38 \mu \mathrm{m}^{3}$ ), were attached onto the mineral surface following a uniform probability model, i.e., every voxel at the mineral surface has the same probability to host a nucleus. Note that the term nucleus is used to refer to a small crystal which has started to grow at the surface, and does not strictly correspond to the critical nucleus discussed in classical nucleation theory. Second, a growth stage follows the nucleation stage. Cubic crystals of 1,8 or 27 voxels were added to the nuclei. They can be attached at the surface of the nuclei only to promote uniform precipitation, or added in a cumulative way to any crystals of the domain to promote non-uniform precipitation. It is also possible to set up the growth from both the nuclei and the original surface of one or several solids in order to induce a mix of growth and nucleation at the same time. The growth is repeated step by step until a desired fraction of the pore space has been filled.

In this study, four different scenarios ( $\mathrm{Sc} 1$ to $\mathrm{Sc} 4)$ of precipitation were tested: (1) uniform growth at the surface of both solid 1 and solid 2, (2) no crystal growth at the surface of solid 1 and uniform growth at the surface of solid 2, (3) no crystal growth at the surface of solid 1 and non-uniform nucleation and growth at the surface of solid 2 using a low density of nucleus (filling $0.1 \%$ of the pore volume) at the surface of solid 2, and (4) no crystal growth at the surface of solid 1 and non-uniform nucleation and growth at the surface of solid 2, using a high density of nucleus at the surface of solid 2 (filling $0.5 \%$ of the pore volume). The different scenarios are illustrated in Figure 10. Scenario 1 (Sc1) is the simplest and corresponds to uniform precipitation over essentially the entire surface of the porous medium. This scenario could occur if the column were composed entirely of calcite spar. In this scenario, the nuclei cover $31 \%$ of the surface of solids 1 and 2 in contact with fluid. Growth of cubes of 1 voxel was imposed 
only at the surface of both the nuclei and the minerals to obtain a relatively smooth surface. Scenario 2 (Sc 2 ) is close to what took place in REAC-1, with uniform growth of calcite onto spar crystals and no growth on glass beads, which are considered to be entirely non-reactive in this case (no nucleation is possible).

The nuclei cover $67 \%$ of the surface of solid 2 in contact with fluid. Successive growth of cubes of 8 and 1 voxels was imposed only at the surface of both the nuclei and solid 2 to obtain a very smooth surface at the end. Scenario 3 (Sc 3) is close to what occurred in REAC-3, with complex, non-uniform growth of calcite crystals on aragonite beads, with the exception that glass beads are also considered in the simulations as totally non-reactive in contrast to what was observed during the experiment (some growth on glass beads did occur). The nuclei cover $4 \%$ of the surface of solid 2 in contact with fluid. Growth of cubes of 27 voxels is cumulative at the surface of the nuclei only. Scenario 4 (Sc 4) is similar to Sc 3, but with a higher density of nuclei at the surface of solid $2(18 \%)$.

After the nucleation stage, two stages (stage 1 and 2) of growth were imposed in the pore evolution modeling. The porosity was reduced by approximately $3.7 \%$ after stage 1 (corresponding to the average decrease of porosity in pore-scale volumes SubVol-REAC-1 and SubVol-REAC-3), and by approximately $7.4 \%$ after stage 2 so as to produce a porosity decrease two times that of the experiments.

Figure 10. Scenarios of precipitation Sc1 to Sc4, shown as: (a) cross-sections at stage 1 (corresponding to a porosity reduction of $\sim 3.7 \%$ ), (b) cross-sections at stage 2 (corresponding to a porosity reduction of $\sim 7.4 \%$ ), and (c) 3D volumes at Stage 2 . New precipitate is shown in white.

\subsection{Flow simulation results}

For each scenario of precipitation ( $\mathrm{Sc} 1$ to $\mathrm{Sc} 4$ ) generated by the pore evolution model, permeability and flow changes were computed as the porosity decreased due to calcite precipitation. The results are presented in Table 5 and can be compared with the results obtained for the samples REAC-1 and REAC-3. The changes in permeability are shown as a function of porosity (Figure 11a) and roughness changes $\left(S / S_{0}\right)$ (Figure 11b). There is a cumulative effect of porosity decrease and roughness increase contributing to the decrease in permeability. Initially, permeability decreases as the porosity decreases. At the end of stage 1, the permeability reduction is between $72 \%$ and $54 \%$, depending on the precipitation scenario. By comparison, the permeability changes of SubVolREAC-1 and SubVolREAC-3 are between these values (Figure 11a). Pore roughness (Figure 11b) is also a parameter contributing to the permeability 
decrease by increasing the pressure gradients at the fluid-mineral interface: the highest permeability

Figure 11. (a) Permeability versus porosity (normalized to initial permeability $\boldsymbol{k}_{D 0}$ and porosity $\phi_{0}$, respectively) for the different pore-scale volumes SubVol-REAC-1 and SubVol-REAC-3 and scenarios Sc1 to Sc4. (b) Permeability versus roughness changes.

Under constant flow rate boundary conditions, the consequence of mineral precipitation is an increase of both the average $(\bar{u})$ and maximum $\left(u_{\max }\right)$ velocities within the porous media (Figure 12). Average fluid velocity and standard deviation of the distribution of velocities also depend on the surface roughness, and is greatest for scenarios for which the increase in roughness is the highest, i.e., Sc3 and Sc4 (Table 5). The fluid velocity distribution is broader when roughness is highest (Figure 13), which confirms the trend observed with the pore-scale volumes SubV-REAC-1 and SubV-REAC-3. More precisely, the principal differences are observed for the slowest $\left(u / u_{p}<0.1\right)$ and highest $\left(u / u_{p} \sim 10\right)$ velocities. The flow field is also more affected in the vicinity of the fluid-rock interface for Sc3 and Sc4 (Figure 14), and becomes more heterogeneous with the development of areas with low flow velocities (i.e., "immobile zones"). Although the average velocity increases close to the interface due to the increases in roughness, a larger number of slow fluid flow volumes of velocity $\sim 0$ were noted.

Figure 12. (a) Average fluid velocity versus maximum velocity in the different sub-volumes (SubVolREAC-1, SubVolREAC-3 and scenarios Sc1 to Sc4 at stage 1 and 2 of growth). (b) Average fluid velocity in the vicinity of the fluid-rock interface, i.e., at a distance of $9 \mu \mathrm{m}$ (i.e., 2 voxels) maximum from the solid phase (for SubVolREAC-1, and the two scenarios with the lowest and highest roughness $S / S_{0}$, i.e., Sc2 and Sc4, respectively). 
Figure 13. Normalized fluid velocity distribution for the different scenarios Sc1 to S4 at stage 2 (i.e., porosity reduction of $\mathbf{7 . 4 \%}$ ), with comparison to the pore-scale volume SubV-REAC-1-initial. The histograms are provided in $\log -\log (a)$ and (b) semi-log plots.

Figure 14. 2D cross-section of the flow velocities (a) perpendicular and (b) parallel to the flow main direction for the different scenarios Sc1 to Sc4, stage 1. White arrows underline areas where flow becomes more heterogeneous compared to Sc1.

Table 5. Permeability and flow properties for the different scenarios of precipitation. Porosity at stage 1 is about the average porosity of the two sub-volumes SubV-REAC-1-final and SubV-REAC3-final.

\begin{tabular}{|l|c|c|c|c|c|c|c|c|c|}
\hline Scenario & & \multicolumn{2}{|c|}{ Sc1 } & \multicolumn{2}{c|}{ Sc2 } & \multicolumn{2}{c|}{ Sc3 } & \multicolumn{2}{c|}{ Sc4 } \\
\hline & initial & stage 1 & stage 2 & stage 1 & stage 2 & stage 1 & stage 2 & stage 1 & stage 2 \\
\hline$k_{D}\left(\times 10^{-12} \mu \mathrm{m}^{2}\right)$ & $115^{*}$ & 73 & 55 & 82 & 63 & 61 & 38 & 64 & 41 \\
\hline $\bar{u} \pm \sigma\left(\mu \mathrm{m} \cdot \mathrm{s}^{-1}\right)$ & $19.5 \pm$ & $22.2 \pm$ & $25.3 \pm$ & $22.2 \pm$ & $25.7 \pm$ & $22.8 \pm$ \\
14.6 & 17.3 & 19.1 & 16.7 & 18.8 & 18.2 & $26.8 \pm$ & $22.7 \pm$ & $26.3 \pm$ \\
& 11.5 & 12.9 & 14.5 & 12.9 & 14.5 & 12.8 & 14.3 & 12.8 & 21.9 \\
\hline$u_{P}\left(\mu \mathrm{m} \cdot \mathrm{s}^{-1}\right)$ & & & & 14.3 \\
\hline
\end{tabular}

527 *Identical initial permeability as SubVol-REAC-1 for every scenario.

\section{5. Discussion}

\subsection{Calcite nucleation and growth}

531 The heterogeneous statistical distributions, shapes, growth rates and growth velocities of the new crystals 532 within the columns are best explained by a combination of heterogeneous nucleation and subsequent 533 crystal growth. According to nucleation theory, the energy barrier for nucleation, $\Delta g_{n}$, depends on the 
degree of fluid supersaturation with respect to the nucleating mineral, $(1-\Omega)$, and on the interfacial free energy, $\alpha$, e.g., [17]: $\Delta g_{n} \propto \alpha^{3} /(1-\Omega)^{2}$. The lack of measurable precipitation with XMT at a distance of about $1.8 \mathrm{~mm}$ from the column inlet on glass beads and about $4.7 \mathrm{~mm}$ on aragonite, together with the fact that precipitation was not detected with SEM on glass beads and on many of the aragonite ooids in the distal portion of the columns (close to the exit) suggest that a high degree of supersaturation is required to lower the energy barrier for nucleation on the non-calcite-based material. In contrast, calcite spar crystals are covered uniformly by a thin layer of new precipitate. Lin and Singer [35] observed in short-term experiments that a saturation index $(\log \Omega)$ of 0.72 was insufficient to allow nucleation of calcite on quartz or dolomite seed materials, although heterogeneous nucleation did take place on calcite . Liolou et al. [34] also observed no precipitation on quartz for solutions with a saturation index $(\log \Omega)$ below 0.73 . In our experiments, an evaluation using geochemical model JChess [59] based on an estimation of the solution composition that took into account the mass of calcite precipitated along the flow direction indicates a critical saturation index ( $\log \Omega_{\text {crit }}$ ) for nucleation on glass beads of $\sim 1.26$ in the experiments. In contrast, a saturation index $(\log \Omega)$ of 1.20 at the REAC-1 column outlet was sufficient to allow nucleation on calcite spar, but made it more difficult or impossible on aragonite ooids. It seems that the surface area that allowed initiation of calcite precipitation is correlated with the energy barrier for nucleation which might explain why only sparse calcite crystals are observed on glass beads, while $92 \%$ of aragonite surface of SubVol-REAC-3 and almost 100\% of calcite spar surface of SubVol-REAC-1 were covered by newly precipitated crystals.

Stockmann et al. [33] observed different induction times for calcite nucleation during mixed-flow precipitation experiments at $25^{\circ} \mathrm{C}$ in the presence of different solid substrates. For calcite and other silicate substrates, precipitation was measurable within half a day, while it took up to 5 days for precipitation to be detectable on basaltic glass. We have no indication of the time required for nucleation on glass beads in the columns, but the difference in size of neighboring crystals (e.g., Figure 5b) suggests that the induction time for nucleation may contribute to the heterogeneity of crystal size distributions.

Crystal shape is also highly dependent on the growth substrate. Indeed, the interfacial free energy is reduced when the atomic structure of the substrate surface closely matches a particular plane of the nucleating phase (minimizing the lattice strain) and the substrate presents a set of chemical functionalities that promotes strong bonding to the nucleus [17]. The degree of epitaxy, which can be compared to the degree of matching between the substrate and the overgrowth crystals, directly constrains crystal growth, e.g., [60]. Starting from isolated nuclei, calcite grows as randomly oriented rhombohedra on glass beads, whereas growth occurs layer-by-layer after two-dimensional surface nucleation on calcite spar [36]. The non-equivalent crystal lattice of aragonite (orthorhombic system) makes it difficult for calcite to grow on 
its surface compared to calcite spar (trigonal system). Consequently, three-dimensional island growth is observed. The polyhedral shape of crystals on aragonite is therefore quite surprising, but might be the result of a release of $\mathrm{Sr}\left(1.110^{-6} \mathrm{M}\right.$ on average at the column outlet) by the ooids (which $\mathrm{Sr} / \mathrm{Ca}$ ratio is 1.4 $10^{-2}$ ) during the experiment. This interpretation is perhaps supported by the observation that the shapes of crystals growing on glass beads are not affected. Sr is known to affect calcite surface morphology during growth by scalloping the obtuse and calcite acute step edges [61, 62], although no effect on step velocities has been measured at such low concentrations. However, a concentration gradient may exist at the surface of aragonite ooids, leading very locally to higher concentrations of $\mathrm{Sr}$.

Precipitation rates as a function of crystal growth velocities and growth rates are also highly variable. Precipitation rate at the column-scale is highly dependent on the saturation index, with the highest rates occurring near the column inlets. Reactive transport modeling of REAC-1 [36] has shown that a good fit of experimental data was obtained using a nearly linear rate expression of eq (1), with $k=1.7910-9$ $\mathrm{mol} \cdot \mathrm{m}^{-2} \cdot \mathrm{s}^{-1}$ and $n=1.12$, suggesting that spiral growth is the main mechanism of precipitation. However, a reasonable agreement was also obtained using a mixed-control reaction combining multi-source spiral growth with a higher order rate expression (as suggested by [63]).

For individual crystals, growth velocities and rates depend on saturation index and crystal orientation, shape and growth competition. The distance used to calculate the growth velocity is the maximal length normal to the substrate surface, so that the velocity depends largely on the crystal shape and orientation. For example, orientation of the longest crystal diagonal perpendicular to the substrate surface will result in highest velocities. In addition, the different facets of a crystal generally exhibit different growth rates, e.g., [8, 64, 65]. Finally, growth competition, which is highly visible on aragonite surfaces (Figure 5d), also involves variation of growth rate over time $[3,66]$.

\subsection{Porosity, permeability and flow}

These interpretations concerning calcite nucleation and growth indicate that non-uniform precipitates can develop readily at the pore-scale even if the reactions are kinetically-controlled. Development of heterogeneity is expected in rocks containing multiple minerals for which surface properties for nucleation and growth differ. The pores that experience the development of pore-scale heterogeneity as a result of precipitation exhibit a higher reduction in permeability compared to those that experienced uniform precipitation. Reduction in permeability is linked to the decrease of porosity [38] through the reduction in the pore-throat size. However, similar reductions in porosity can lead to differing reductions in permeability. These differences arise from the development of pore roughness that is linked to the location and size of the newly formed crystals. More importantly, roughness increase causes the decrease in 
average fluid velocity in the vicinity of the mineral surface (despite the fact that the maximum velocity is increased). Although it has not been quantified in this study, this can have significant implications for the hydrodynamics and the transport of reactants and products near the fluid rock interface. For example, [67] explained the origin of early breakthrough and long tailing plume behavior in various carbonate rock samples by the shape of the probability density function of normalized velocity, which exhibits different characteristics in terms of magnitude of the main velocity peak and spreading between low and high velocities. Transport in samples with a relative narrow spread of velocities is characterized by a small peak (of probability of molecular displacement) representing stagnant portion of the pore space and a dominant secondary peak of solute moving at approximately the average flow velocity, while transport in samples with a wider velocity distribution is characterized by a significant peak of stagnant solute and an elongated tail of moving fluid (see [67] for more details).

\section{Conclusion}

We performed a set of experiments to obtain detailed measurements of calcite precipitation in two porous columns, one consisting of a mix of calcite spar and glass beads, another consisting of aragonite ooids and glass beads. XMT has provided direct information about the porous geometry changes and localization of the precipitates. Despite the similar chemical compositions of the inlet solution and flow conditions, the shape, size and distribution of the new calcite crystals have shown to be very different depending on the material substrate. The results indicate that both calcite nucleation and growth stages are important in the development of non-uniform precipitation patterns. As a consequence, the pore geometry evolution was very different in the two experiments and led to differing evolution of pore roughness. The modeling analysis carried out here to supplement the XMT characterization highlighted the significance of the pore-scale distribution of the new precipitates on the evolution of permeability. Permeability changes are linked to the porosity reduction as well as to the changes of the pore surface roughness. Roughness increase in the vicinity of grains increases the heterogeneity of the flow field and affects the transport of reactants and products near the mineral surface.

The results also demonstrate that the spatial distribution of different minerals should be taken into account for the calculation of permeability changes in porous rocks, as both localization of precipitation and precipitation patterns depend on it. Further investigation is needed to explore systems that experience higher porosity decreases, i.e., down to the point where the percolation threshold is reached, although it can be difficult to obtain experimentally a constant decrease of the porosity along the porous media. Increasing the number of XMT data sets during an experiment could also confirm that the growth rates and velocities are not constant with space and time. 
2

3

This study does not consider the impact of hydrodynamics changes close to the fluid-mineral interface on transport, and possible feedbacks between chemical reaction and transport, which could be significant. One consequence of the growth of crystals is the generation of stagnant or low velocity zones in the vicinity of rough crystals, while the reduction of pore throats implies an increase of the fluid velocity through them. Consequently, changes of Damköhler and Péclet numbers with space and time [14] might reduce or increase the probability of nucleating and growing new crystals. Such an analysis will be only possible with a full pore-scale transient reactive transport model.

\section{Acknowledgments}

639 This work was supported in part by the Center for Nanoscale Control of Geologic $\mathrm{CO}_{2}$, an Energy 640 Frontier Research Center funded by the U.S. Department of Energy, Office of Science, Basic Energy 641 Sciences under Contract No. DE-AC02-05CH11231 to Lawrence Berkeley National Laboratory. 642 Synchrotron XMT work was performed at the Advanced Light Source, Beamline 8.3.2. Joern Larsen 644 (Université de Lille 1) are thanked for their assistance with ICP-MS, XMT acquisition, SEM, Raman, and 645 preparation of thin sections, respectively. (ESD/LBNL), Alastair MacDowell (ALS/LBNL), Philippe Recourt, Sandra Ventalon and Sylvie Regnier 
652 [1] Tenthorey E, H Scholz, E Aharonov, A Léger. Precipitation sealing and diagenesis 1. Experimental 653 results. J Geophys Res. 103 (1998) 23951-23967.

654 [2] Buhmann D, W Dreybrodt. The kinetics of calcite dissolution and precipitation in geologically 655 relevant situations of karst areas. 1. Open system. Chem Geol. 48 (1985) 189-211.

656 [3] Hilgers C, JL Urai. Experimental study of syntaxial vein growth during lateral fluid flow in transmitted 657 light: first results. Journal of Structural Geology. 24 (2002) 1029-1043, doi: 10.1016/s0191658 8141(01)00089-x.

659 [4] Lackner KS. A Guide to $\mathrm{CO}_{2}$ sequestration. Science. 300 (2003) 1677-1678.

660 [5] Kampman N, M Bickle, M Wigley, B Dubacq. Fluid flow and $\mathrm{CO}_{2}$-fluid-mineral interactions during 661 CO2-storage in sedimentary basins. Chem Geol. 369 (2014) 22-50, doi: 10.1016/j.chemgeo.2013.11.012.

662 [6] Kaszuba J, B Yardley, M Andreani. Experimental perspectives of mineral dissolution and precipitation 663 due to carbon dioxide-water-rock interactions, in: DJ DePaolo, DR Cole, A Navrotsky, IC Bourg, (Eds.). 664 Geochemistry of Geologic $\mathrm{CO}_{2}$ Sequestration Reviews in Mineralogy and Geochemistry, 2013, pp. 153665188.

666 [7] Nielsen AE. Electrolyte crystal-growth mechanisms. Journal of Crystal Growth. 67 (1984) 289-310, 667 doi: 10.1016/0022-0248(84)90189-1.

668 [8] Teng HH, PM Dove, JJ De Yoreo. Kinetics of calcite growth: Surface processes and relationships to 669 macroscopic rate laws. Geochim Cosmochim Acta. 64 (2000) 2255-2266, doi: 10.1016/s0016$6707037(00) 00341-0$.

671 [9] Blum AE, AC Lasaga. Monte Carlo simulations of surface reaction rate laws, in: W Stumm, (Ed.). 672 Aquatic Surface Chemistry: Chemical Processes at the Particle-Water Interface. John Wiley \& Sons, New 673 York, 1987, pp. 255-292.

674 [10] Hoefner ML, HS Fogler. Pore evolution and channel formation during flow and reaction in porous 675 media. AIChE Journal. 34 (1998) 45-53. 
[11] Steefel CI, AC Lasaga. Evolution of dissolution patterns: Permeability change due to coupled flow and reaction, in: D Melchior, RL Bassett, (Eds.). Chemical Modeling of Aqueous Systems II. American Chemical Society, Washington DC, 1990, pp. 212-225.

[12] Crawshaw JP, ES Boek. Multi-scale Imaging and Simulation of Structure, Flow and Reactive Transport for $\mathrm{CO}_{2}$ Storage and EOR in Carbonate Reservoirs, in: DJ De Paolo, DR Cole, A Navrotsky, IC Bourg, (Eds.). Geochemistry of Geologic $\mathrm{CO}_{2}$ Sequestration. Reviews in Mineralogy and Geochemistry, 2013, pp. 431-458.

[13] Steefel CI, S Molins, D Trebotich. Pore scale processes associated with subsurface $\mathrm{CO}_{2}$ injection and sequestration, in: DJ DePaolo, DR Cole, A Navrotsky, IC Bourg, (Eds.). Geochemistry of Geologic $\mathrm{CO}_{2}$ Sequestration. Reviews in Mineralogy and Geochemistry, 2013, pp. 259-303.

[14] Noiriel C. Resolving time-dependent evolution of pore scale structure, permeability and reactivity using X-ray microtomography. in: CI Steefel, E Emmanuel, L Anovitz, (Eds.). Reviews in Mineralogy and Geochemistry. Mineralogical Society of America, 2015, pp. 247-286.

[15] Golfier F, C Zarcone, B Bazin, R Lenormand, D Lasseux, M Quintard. On the ability of a Darcyscale model to capture wormhole formation during the dissolution of a porous medium. Journal of Fluid Mechanics. 457 (2002) 213-254.

[16] Nancollas G, MM Reddy. Crystallization of calcium carbonate 2. Calcite growth mechanism. Journal of Colloid and Interface Science. 37 (1971) 824-830, doi: 10.1016/0021-9797(71)90363-8.

[17] De Yoreo JJ, PG Vekilov. Principles of crystal nucleation and growth, in: PM Dove, JJ DeYoreo, S Weiner, (Eds.). Biomineralization, 2003, pp. 57-93.

[18] Zhang Y, RA Dawe. Influence of $\mathrm{Mg}^{2+}$ on the kinetics of calcite precipitation and calcite crystal morphology. Chem. Geol. 163 (2000) 129-138.

[19] Wu Y, S Hubbard, KH Williams, J Ajo-Franklin. On the complex conductivity signatures of calcite precipitation. Journal of Geophysical Research-Biogeosciences. 115 (2010) 2156-2202, doi: G00g0410.1029/2009jg001129.

[20] Armstrong R, J Ajo-Franklin. Investigating biomineralization using synchrotron based X-ray computed microtomography. Geophys Res Lett. 38 (2011), doi: 10.1029/2011gl046916.

[21] Dove PM, MF Hochella. Calcite precipitation mechanisms and inhibition by orthophosphate: in situ observations by scanning force microscopy. Geochim Cosmochim Acta. 57 (1993) 705-714.

[22] Dromgoole EL, LM Walter. Inhibition of calcite growth rates by $\mathrm{Mn} 2+$ in $\mathrm{CaCl} 2$ solutions at 10, 25, and 50[deg]C. Geochim Cosmochim Acta. 54 (1990) 2991-3000. 
[23] Ferris FG, V Phoenix, Y Fujita, RW Smith. Kinetics of calcite precipitation induced by ureolytic bacteria at 10 to 20[deg]C in artificial groundwater. Geochim Cosmochim Acta. 68 (2004) 1701-1710.

[24] Inskeep WP, PR Bloom. An evaluation of rate-equations for calcite precipitation kinetics at $\mathrm{pCO}_{2}$ less than 0.01atm and pH greater than 8. Geochim Cosmochim Acta. 49 (1985) 2165-80, doi: 10.1016/00167037(85)90074-2.

[25] Lebron I, DL Suarez. Calcite nucleation and precipitation kinetics as affected by dissolved organic matter at 25[deg]C and pH > 7.5. Geochim Cosmochim Acta. 60 (1996) 2765-2776.

[26] Lin YP, PC Singer, GR Aiken. Inhibition of calcite precipitation by natural organic material: Kinetics, mechanism, and thermodynamics. Environmental Science \& Technology. 39 (2005) 6420-6428.

[27] Ruiz-Agudo E, CV Putnis, C Rodriguez-Navarro, A Putnis. Effect of pH on calcite growth at constant $\mathrm{a}(\mathrm{Ca} 2+) / \mathrm{a}(\mathrm{CO} 32-)$ ratio and supersaturation. Geochim Cosmochim Acta. 75 (2011) 284-296, doi: 10.1016/j.gca.2010.09.034.

[28] Shaojun Z, A Mucci. Calcite precipitation in seawater using a constant addition technique: A new overall reaction kinetic expression. Geochim Cosmochim Acta. 57 (1993) 1409-1417.

[29] Shiraki R, SL Brantley. Kinetics of near-equilibrium calcite precipitation at $100^{\circ} \mathrm{C}$ - An evaluation of elementary reaction-based and affinity-based rate laws. Geochim Cosmochim Acta. 59 (1995) 1457-1471, doi: 10.1016/0016-7037(95)00055-5.

[30] Stocks-Fischer S, JK Galinat, SS Bang. Microbiological precipitation of $\mathrm{CaCO}_{3}$. Soil Biology and Biochemistry. 31 (1999) 1563-1571.

[31] Zavarin M, HE Doner. Effect of P and Se(IV) on calcite precipitation inhibition. Soil Science. 170 (2005) 612-623.

[32] Stockmann GJ, D Wolff-Boenisch, SR Gislason, EH Oelkers. Do carbonate precipitates affect dissolution kinetics? 1: Basaltic glass. Chem Geol. 284 (2011) 306-316, doi: 10.1016/j.chemgeo.2011.03.010.

[33] Stockmann GJ, D Wolff-Boenisch, N Bovet, SR Gislason, EH Oelkers. The role of silicate surfaces on calcite precipitation kinetics. Geochim Cosmochim Acta. 135 (2014) 231-250, doi: 10.1016/j.gca.2014.03.015.

[34] Lioliou MG, CA Paraskeva, PG Koutsoukos, AC Payatakes. Heterogeneous nucleation and growth of calcium carbonate on calcite and quartz. Journal of Colloid and Interface Science. 308 (2007) 421-428, doi: 10.1016/j.jcis.2006.12.045. 
[35] Lin YP, PC Singer. Effects of seed material and solution composition on calcite precipitation.

Geochim Cosmochim Acta. 69 (2005) 4495-4504, doi: 10.1016/j.gca.2005.06.002.

[36] Noiriel C, CI Steefel, L Yang, J Ajo-Franklin. Upscaling calcium carbonate precipitation rates from pore to continuum scale. Chem Geol. 318-319 (2012) 60-74.

[37] Carman PC. Fluid flow through granular beds. Transaction for Institute of Chemical Engineer. 15 (1937) 150-166.

[38] Reis JC, AM Acock. Permeability reduction models for the precipitation of inorganic solid in Berea sandstone. In Situ. 18 (1994) 347-368.

[39] Xu P, B Yu. Developing a new form of permeability and Kozeny-Carman constant for homogeneous porous media by means of fractal geometry. Adv Water Resour. 31 (2008) 74-81, doi: 10.1016/j.advwatres.2007.06.003.

[40] Ghezzehei TA. Linking sub-pore scale heterogeneity of biological and geochemical deposits with changes in permeability. Adv Water Resour. 39 (2012) 1-6, doi: 10.1016/j.advwatres.2011.12.015.

[41] Wildenschild D, AP Sheppard. X-ray imaging and analysis techniques for quantifying pore-scale structure and processes in subsurface porous medium systems. Adv Water Resour. 51 (2013) 217-246, doi: 10.1016/j.advwatres.2012.07.018.

[42] Lindquist WB, A Venkatarangan, J Dunsmuir, T Wong. Pore and throat size distributions measured from synchrotron X-ray tomographic images of Fontainebleau sandstones. J Geophys Res. 105 (2000) 21509-21527.

[43] Lindquist WB, S Lee, DA Coker, KW Jones, P Spanne. Medial axis analysis of void structure in three-dimensional tomographic image of porous media. J Geophys Res. 101 (1996) 8297-8310.

[44] Al-Raoush RI, CS Willson. Extraction of physically realistic pore network properties from threedimensional synchrotron X-ray microtomography images of unconsolidated porous media systems. J Hydrol. 300 (2005) 44-64, doi: 10.1016/j.jhydrol.2004.05.005.

[45] Noiriel C, P Gouze, D Bernard. Investigation of porosity and permeability effects from microstructure changes during limestone dissolution. Geophys Res Lett. 31 (2004) L24603, doi:10.1029/2004GL021572.

[46] Noiriel C, D Bernard, P Gouze, X Thibaut. Hydraulic properties and microgeometry evolution in the course of limestone dissolution by $\mathrm{CO}_{2}$-enriched water. Oil \& Gas Science and Technology. 60 (2005) 766 177-192. 
[47] Noiriel C, P Gouze, B Made. 3D analysis of geometry and flow changes in a limestone fracture

during dissolution. J Hydrol. 486 (2013) 211-223, doi: 10.1016/j.jhydrol.2013.01.035.

[48] Blunt MJ, B Bijeljic, H Dong, O Gharbi, S Iglauer, P Mostaghimi, et al. Pore-scale imaging and modelling. Adv Water Resour. 51 (2013) 197-216, doi: 10.1016/j.advwatres.2012.03.003.

[49] Dierick M, B Masschaele, L Van Hoorebeke. Octopus, a fast and user-friendly tomographic reconstruction package developed in LabView (R). Meas Sci Technol. 15 (2004) 1366-1370, doi: 10.1088/0957-0233/15/7/020.

[50] Russ JC. The Image Processing Handbook, Sixth Edition. CRC Press, 2011.

[51] Akmal Butt M, P Maragos. Optimum design of chamfer distance transforms. Image Processing, IEEE Transactions. 7 (1998) 1477-1484, doi: 10.1109/83.718487.

[52] Beucher S. The watershed transformation applied to image segmentation. $10^{\text {th }}$ Pfefferkorn Conference on Signal and Image Processing in Microscopy and Microanalysis. Scanning Microscopy International suppl. 6, Cambridge, 1992. pp. 299-314.

[53] Pitas I. Digital image processing algorithms and applications. Wiley, 2000.

[54] Whitaker S. The Method of Volume Averaging, in: K Pub., (Ed.). Theory and Application of Transport in Porous Media. Springer, Dordrecht, 1999, pp. 210.

[55] Bernard D, O Nielsen, L Salvo, P Cloetens. Permeability assessment by 3D interdendritic flow simulations on microtomography mappings of Al-Cu alloys. Mater Sci Eng A-Struct Mater Prop Microstruct Process. 392 (2005) 112-120, doi: 10.1016/j.msea.2004.09.004.

[56] Peyret R, TD Taylor. Computational Methods for Fluid Flow. Springer Verlag, Berlin, 1983.

[57] Chorin AJ. A Numerical Method for Solving Incompressible Viscous Flow Problems. Journal of Computational Physics. 2 (1967) 12-26.

[58] Darcy H. Les fontaines publiques de la ville de Dijon. Dalmont, Paris, 1856.

[59] van der Lee J. Thermodynamic and mathematical concepts of CHESS. Technical report LHM/RD/98/3, Ecole des Mines de Paris, 1998, pp. 99.

[60] Stumm W, JJ Morgan. Aquatic chemistry. Wiley, New York, 2004.

[61] Wasylenki LE, PM Dove, DS Wilson, JJ De Yoreo. Nanoscale effects of strontium on calcite growth: An in situ AFM study in the absence of vital effects. Geochim Cosmochim Acta. 69 (2005) 3017-3027, doi: 10.1016/j.gca.2004.12.019. 
7

[62] Bracco JN, MC Grantham, AG Stack. Calcite Growth Rates As a Function of Aqueous Calcium-toCarbonate Ratio, Saturation Index, and Inhibitor Concentration: Insight into the Mechanism of Reaction and Poisoning by Strontium. Crystal Growth \& Design. 12 (2012) 3540-3548, doi: 10.1021/cg300350k.

[63] Tang JW, M Dietzel, F Bohm, SJ Kohler, A Eisenhauer. $\operatorname{Sr}(2+) / \mathrm{Ca}(2+)$ and (44)Ca/(40)Ca fractionation during inorganic calcite formation: II. Ca isotopes. Geochim Cosmochim Acta. 72 (2008) 3733-3745, doi: 10.1016/j.gca.2008.05.033.

802 [64] Hillner PE, AJ Gratz, S Manne, PK Hasma. Atomic-scale imaging of calcite growth and dissolution 803 in real time. Geology. 20 (1992) 359-362.

804 [65] Paquette J, RJ Reeder. Relationship between surface structure, growth mechanism, and trace element 805 incorporation in calcite. Geochim Cosmochim Acta. 59 (1995) 735-749.

806 [66] Nollet S, C Hilgers, JL Urai. Experimental study of polycrystal growth from an advecting 807 supersaturated fluid in a model fracture. Geofluids. 6 (2006) 185-200, doi: 10.1111/j.1468$808 \quad$ 8123.2006.00142.x.

809 [67] Bijeljic B, P Mostaghimi, MJ Blunt. Insights into non-Fickian solute transport in carbonates. Wat 810 Resour Res. 49 (2013) 2714-2728. 
Figure1

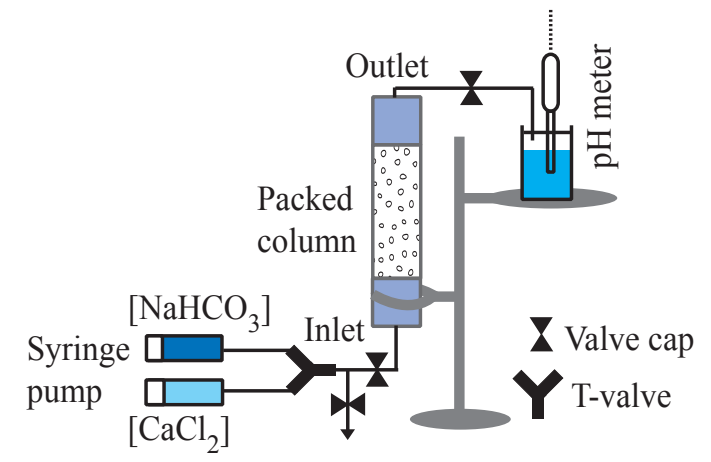

Figure 1. Schematic of the plug-flow column experimental setup 
Figure2

(a)

calcite

spar
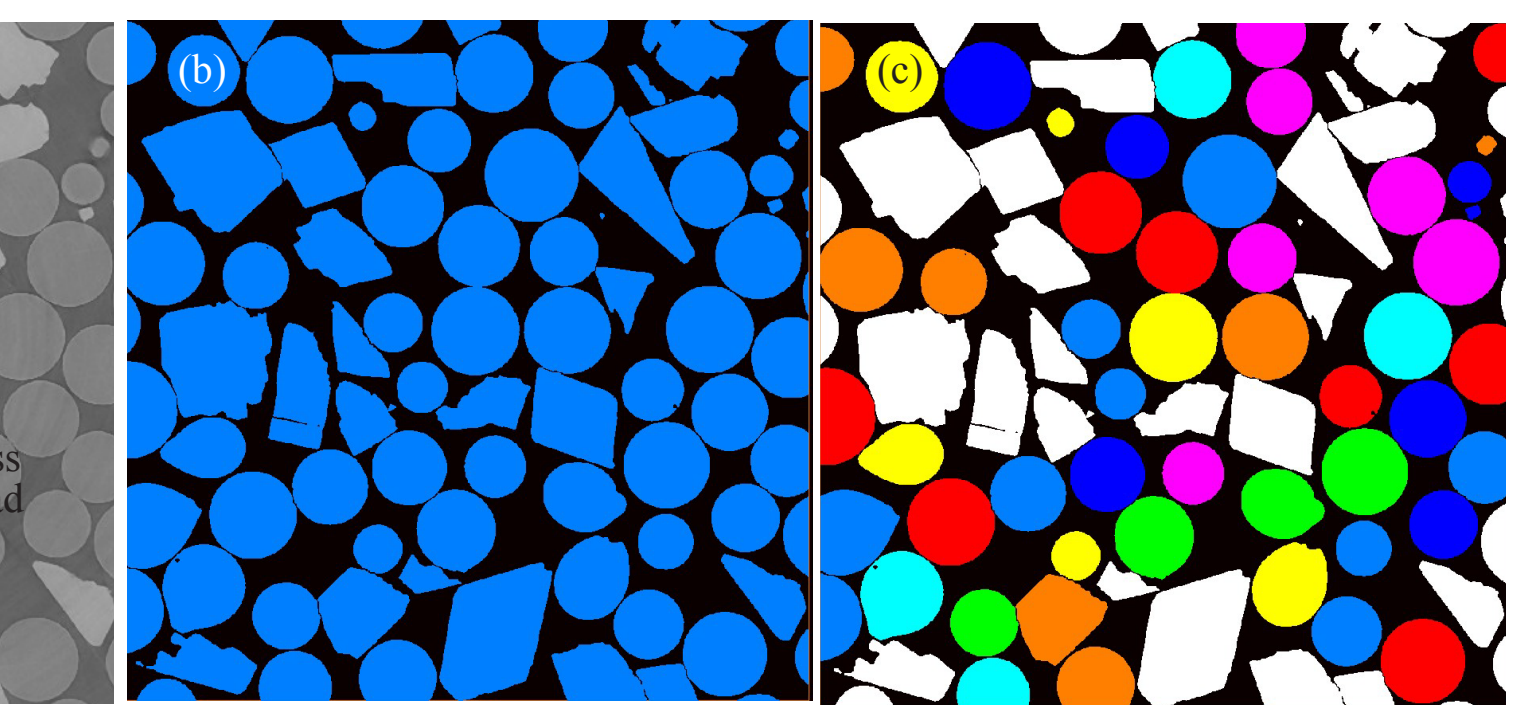


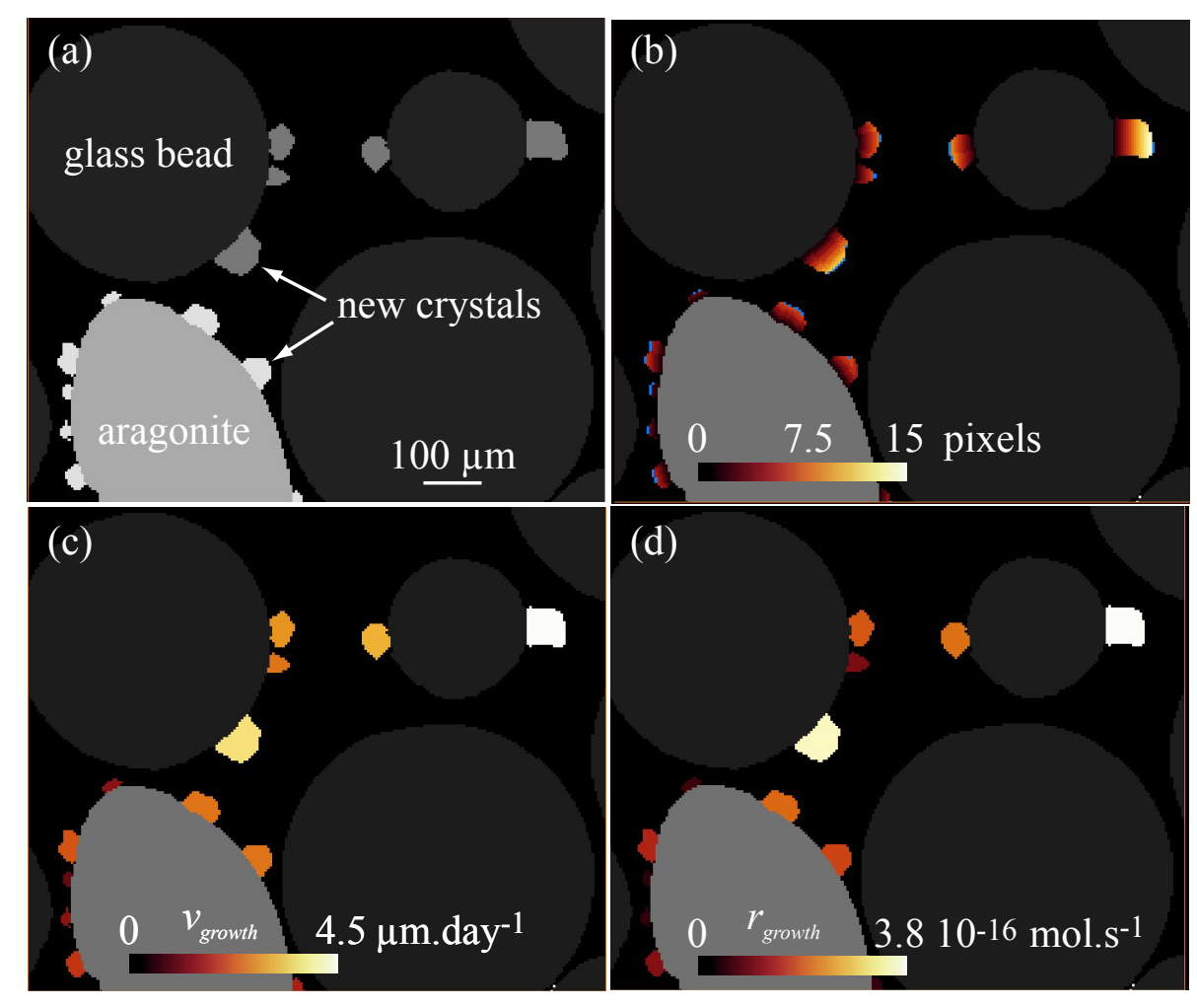

Figure. 

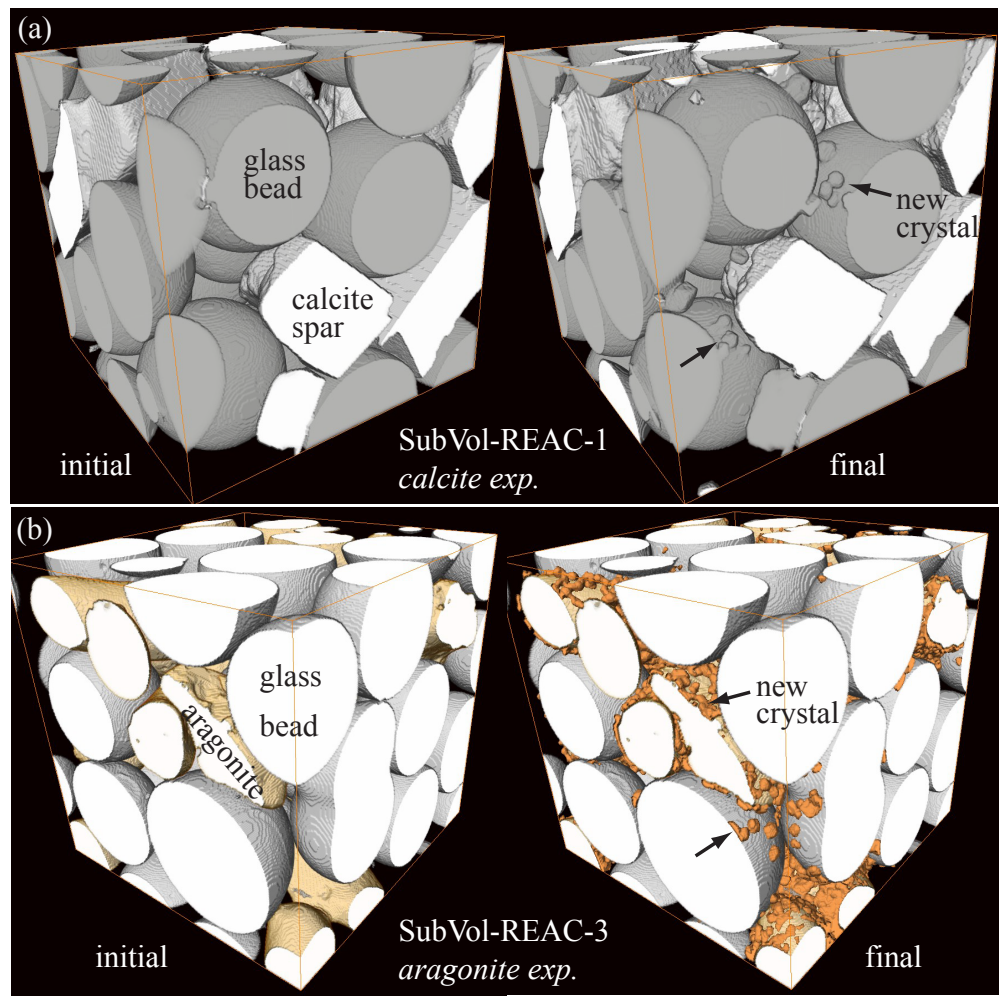
Figure5

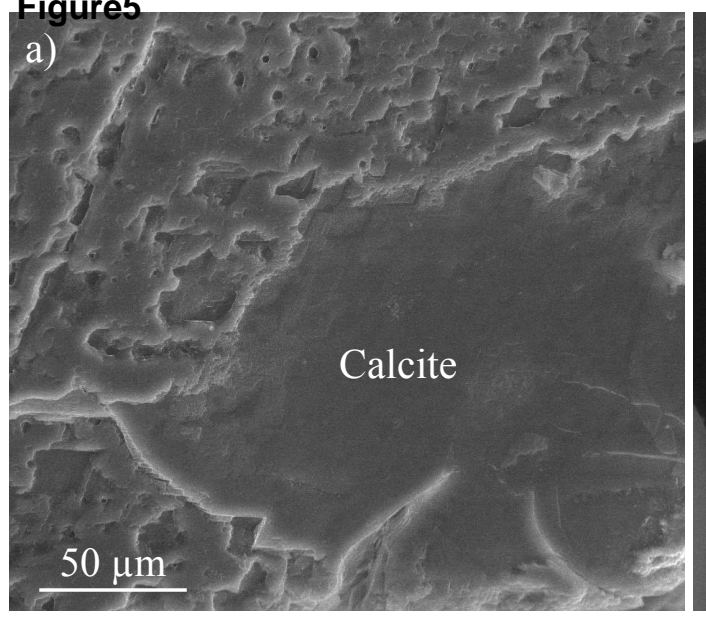

c)

Aragonite

- ooïd

Calcite

$100 \mu \mathrm{m}$
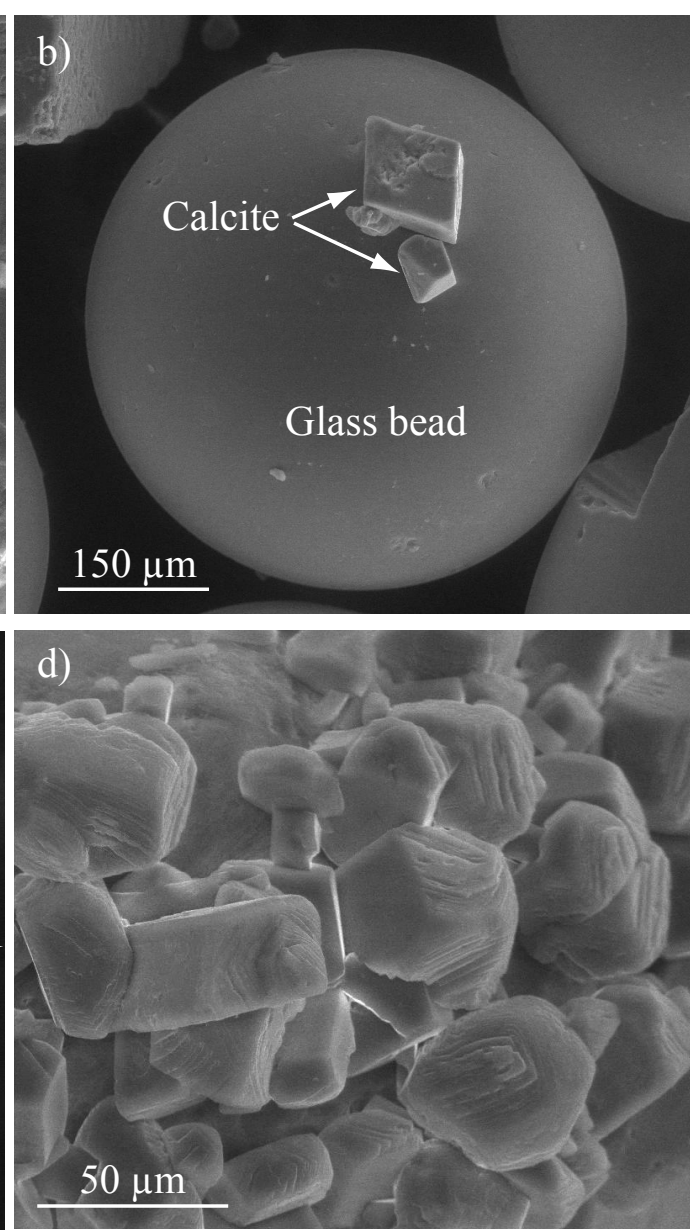


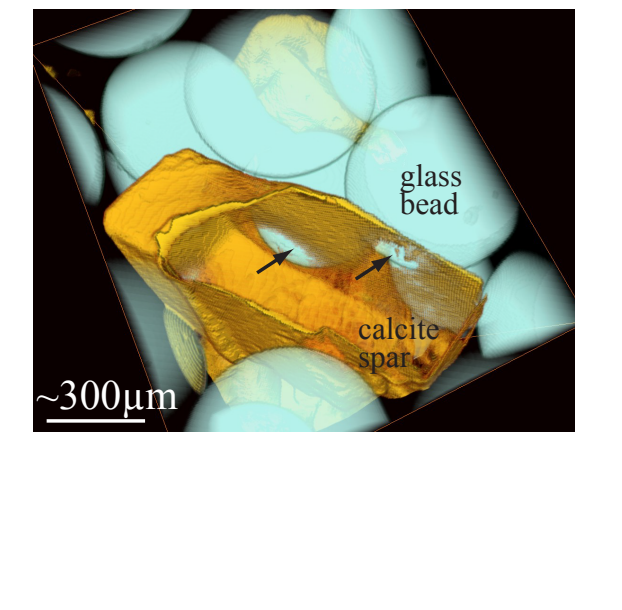

Figure6

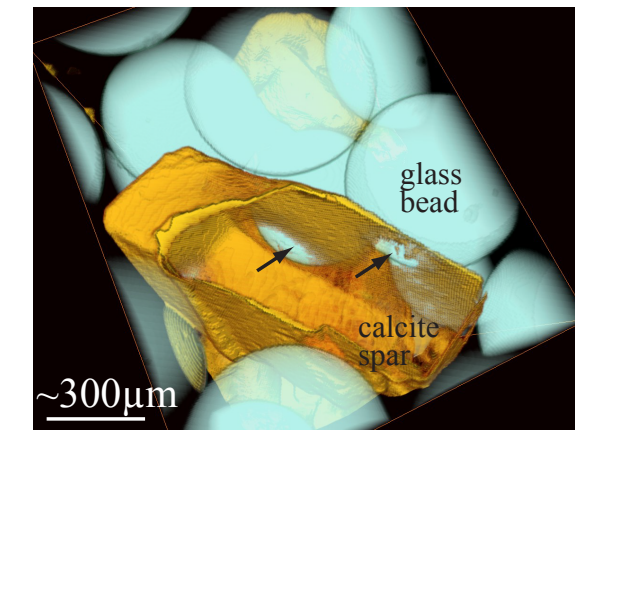

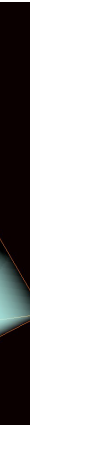

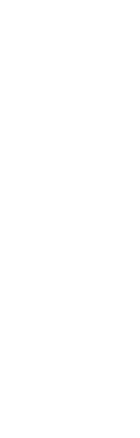

Sa

Figure6

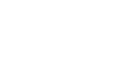

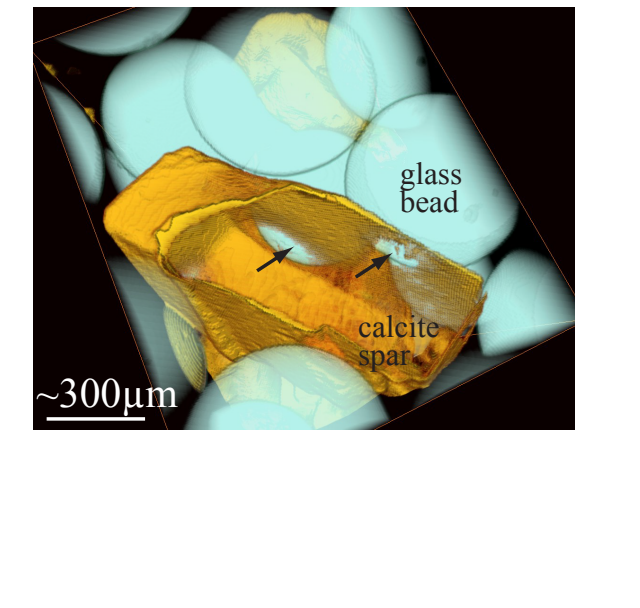


Figure 8

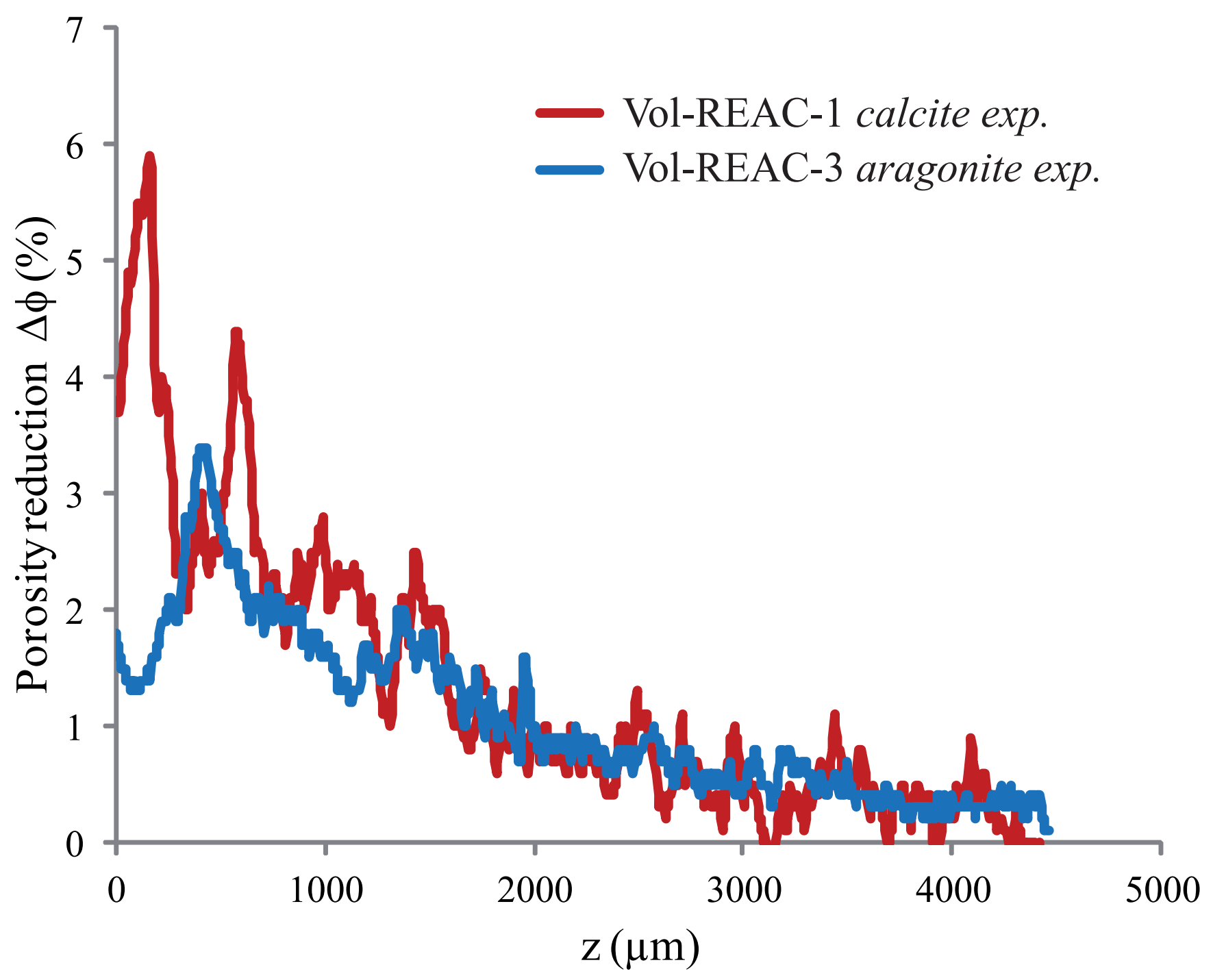


Figure 9
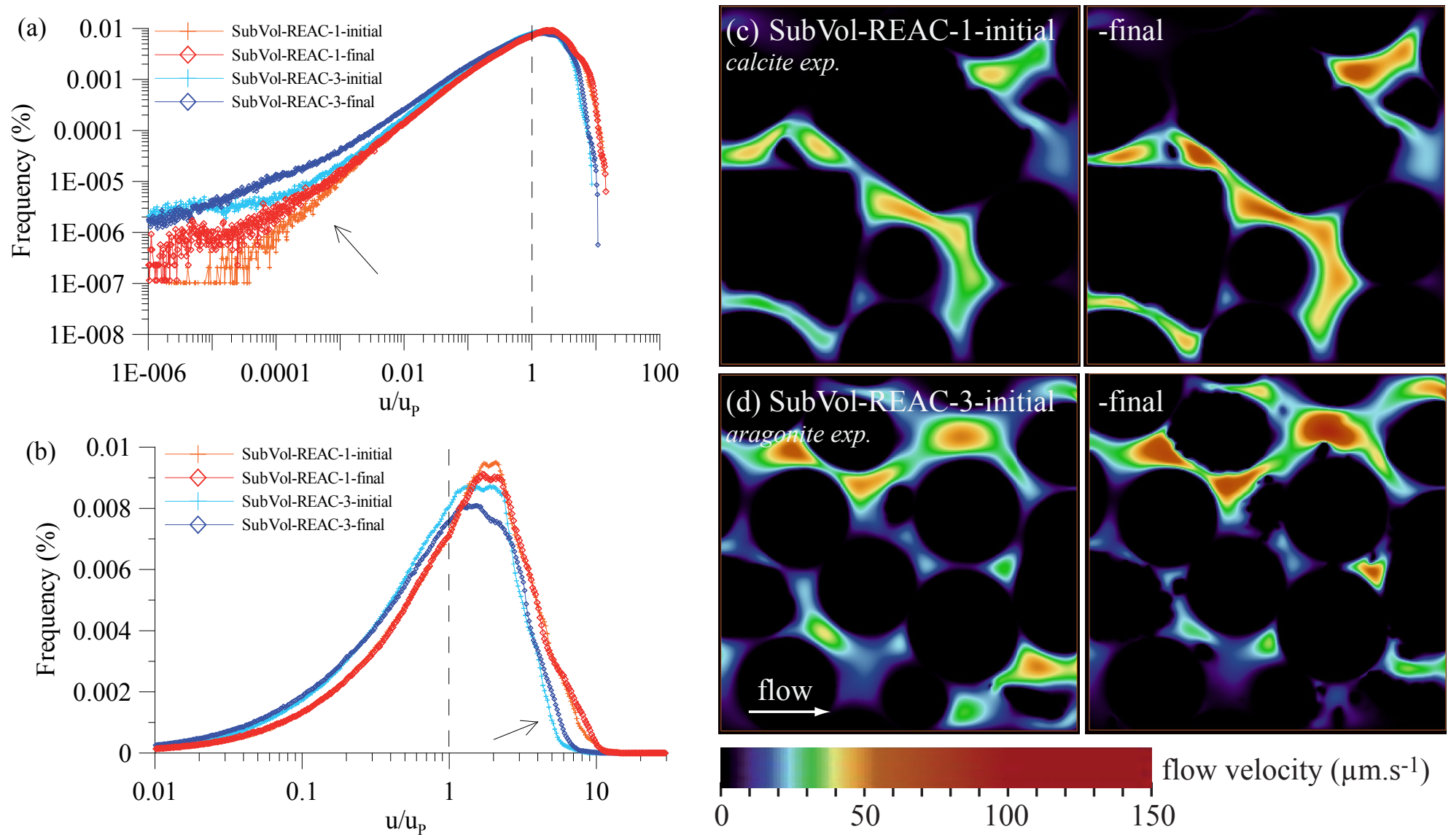

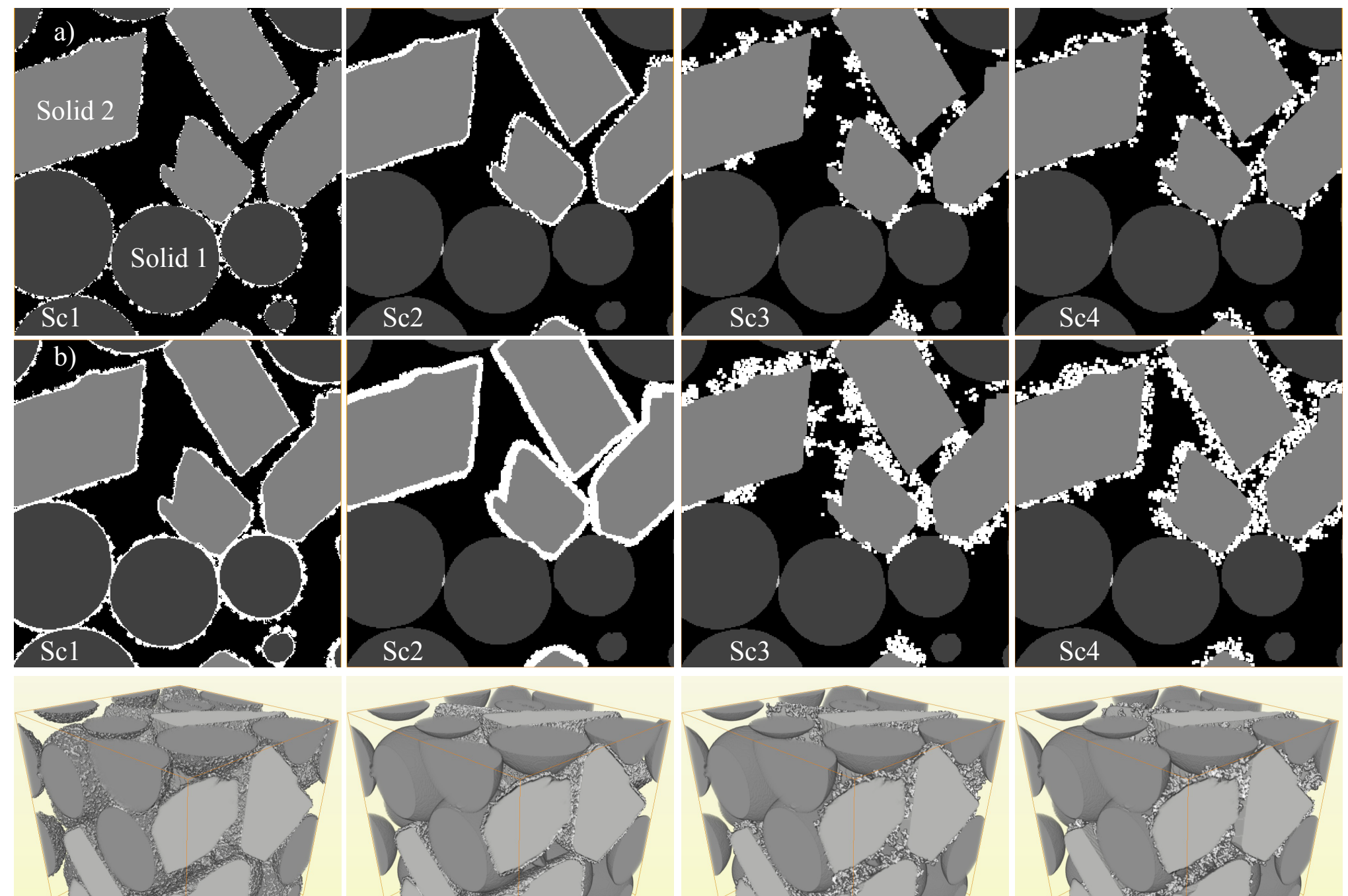

c)
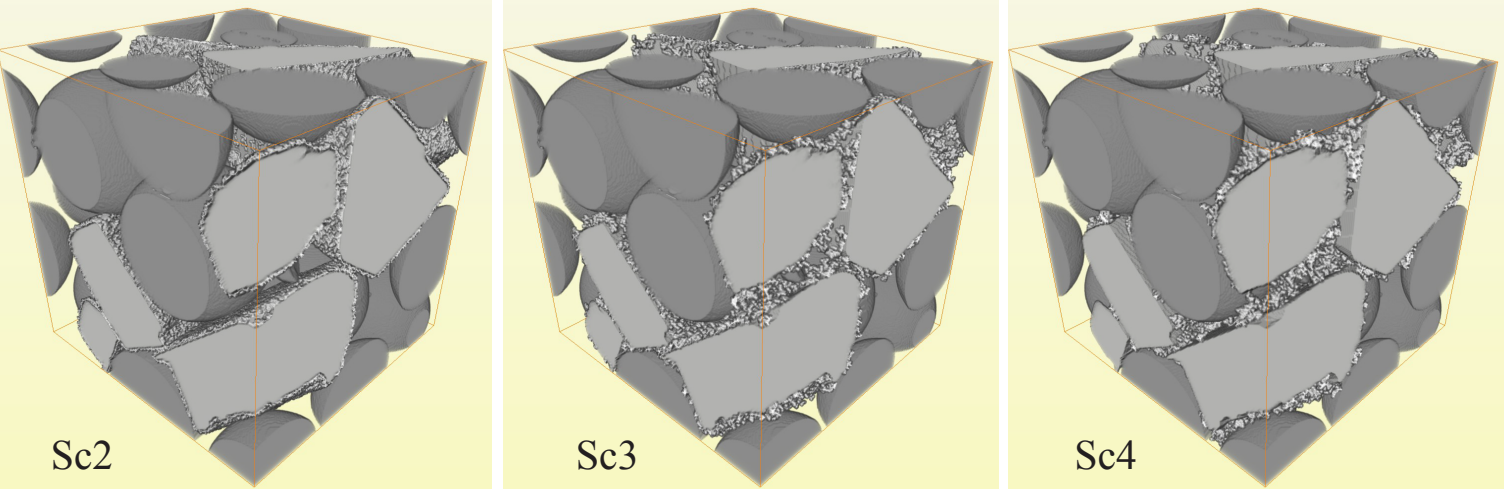
Figure 11

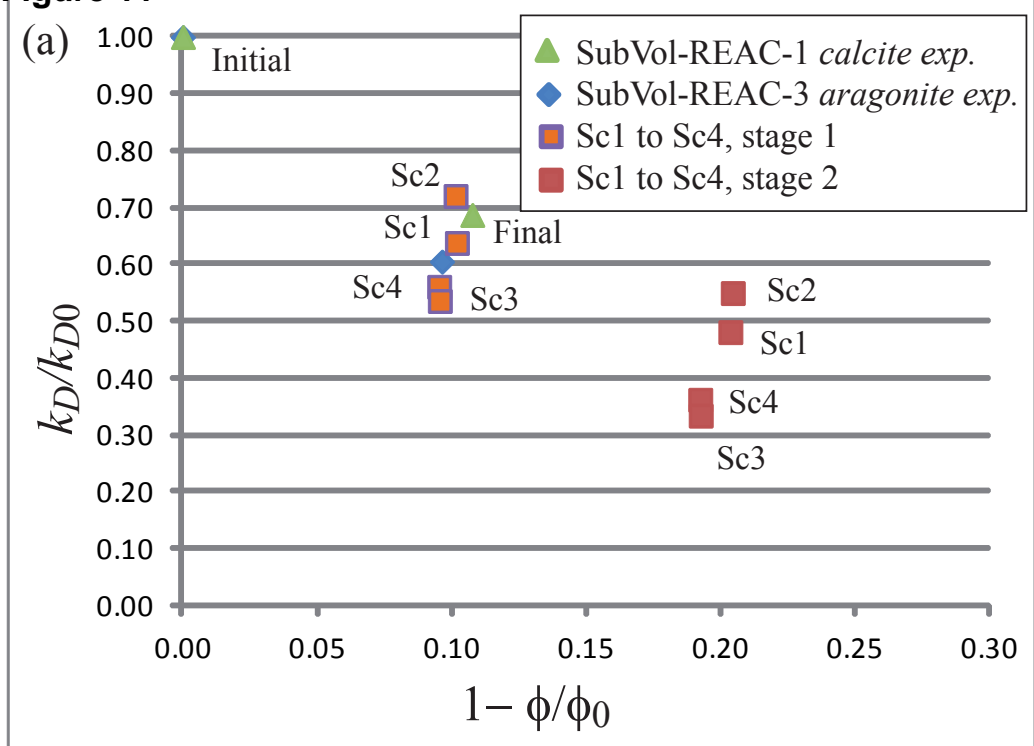

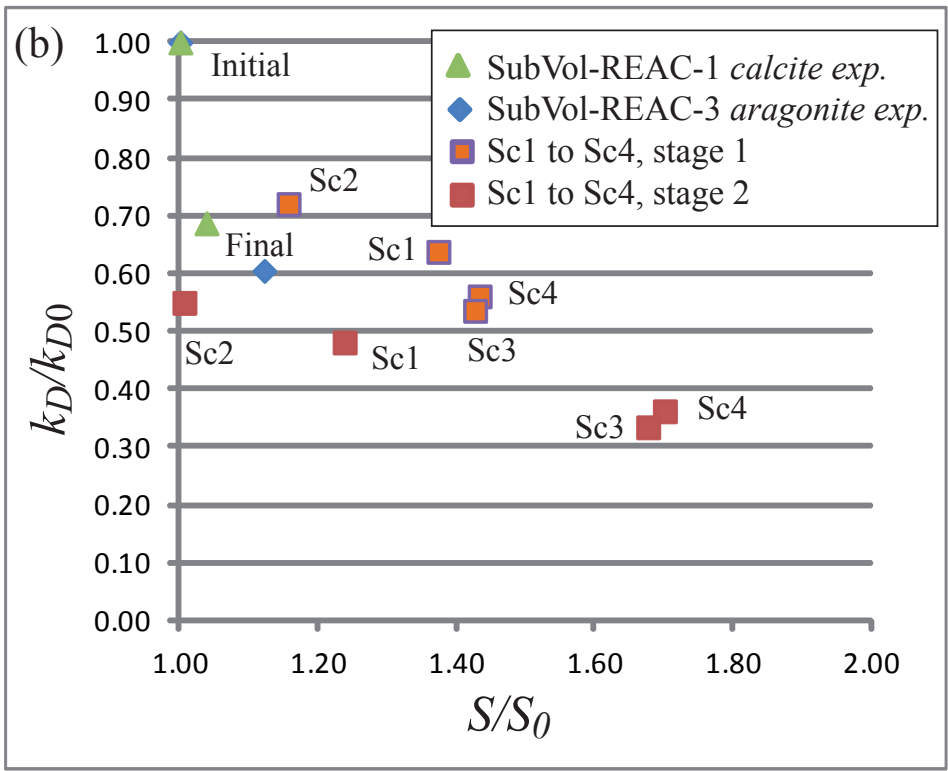




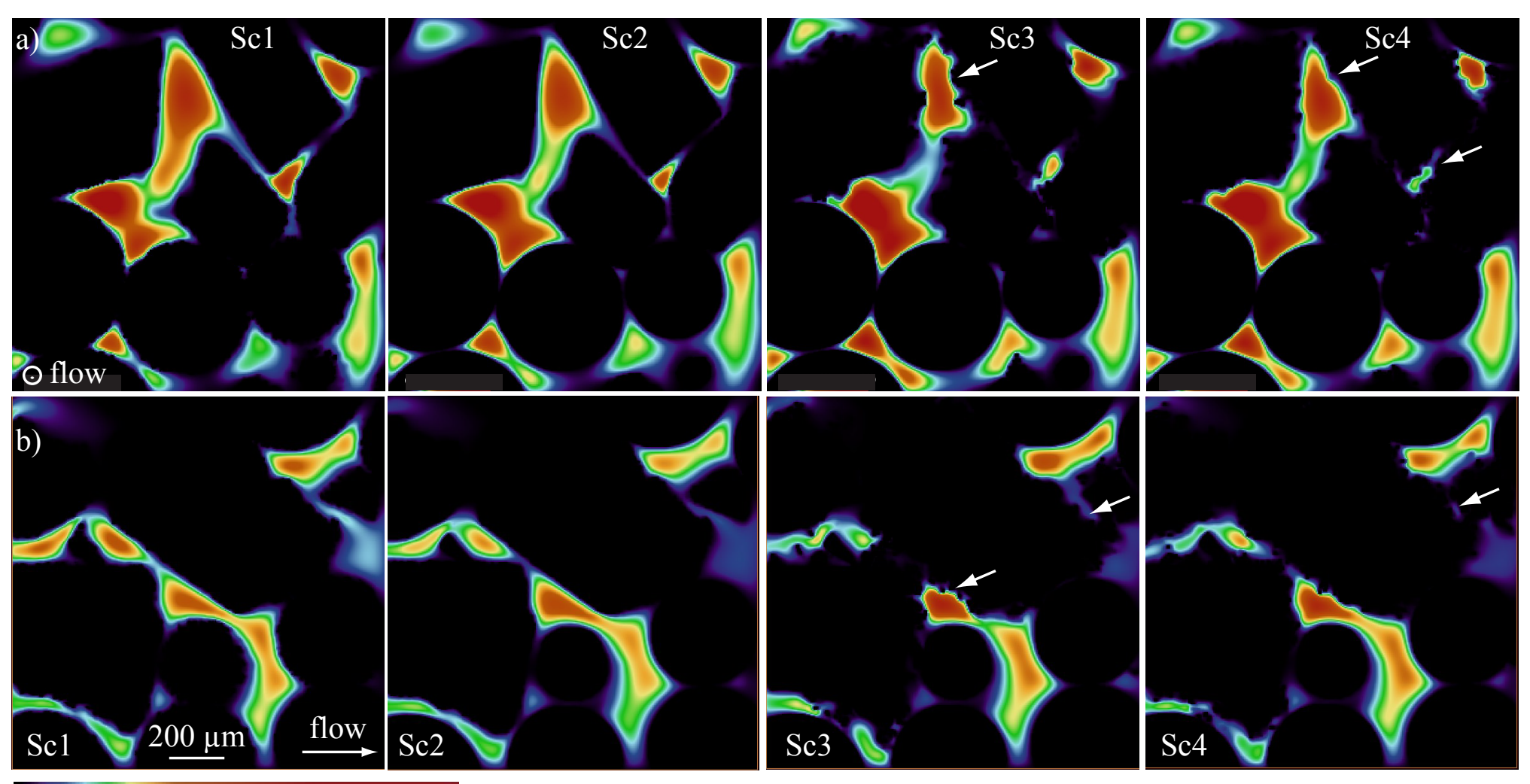

flow velocity $u\left(\mu \mathrm{m} \cdot \mathrm{s}^{-1}\right)$

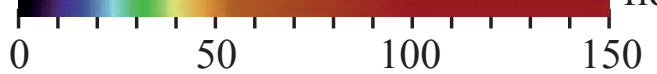

